\title{
Free Vibration Analysis of the Unified Functionally Graded Shallow Shell with General Boundary Conditions
}

\author{
Dongyan Shi, ${ }^{1}$ Shuai Zha, ${ }^{1}$ Hong Zhang, ${ }^{1}$ and Qingshan Wang ${ }^{1,2,3}$ \\ ${ }^{1}$ College of Mechanical and Electrical Engineering, Harbin Engineering University, Harbin 150001, China \\ ${ }^{2}$ College of Mechanical and Electrical Engineering, Central South University, Changsha 410083, China \\ ${ }^{3}$ State Key Laboratory of High Performance Complex Manufacturing, Central South University, Changsha 410083, China
}

Correspondence should be addressed to Hong Zhang; zhanghongyuxin@outlook.com

Received 22 May 2017; Accepted 6 August 2017; Published 11 September 2017

Academic Editor: Toshiaki Natsuki

Copyright (C) 2017 Dongyan Shi et al. This is an open access article distributed under the Creative Commons Attribution License, which permits unrestricted use, distribution, and reproduction in any medium, provided the original work is properly cited.

\begin{abstract}
The free vibration analysis of the functionally graded (FG) double curved shallow shell structures with general boundary conditions is investigated by an improved Fourier series method (IFSM). The material properties of FG structures are assumed to vary continuously in the thickness direction, according to the four graded parameters of the volume distribution function. Under the current framework, the displacement and rotation functions are set to a spectral form, including a double Fourier cosine series and two supplementary functions. These supplements can effectively eliminate the discontinuity and jumping phenomena of the displacement function along the edges. The formulation is based on the first-order shear deformation theory (FSDT) and RayleighRitz technique. This method can be universally applied to the free vibration analysis of the shallow shell, because it only needs to change the relevant parameters instead of modifying the basic functions or adapting solution procedures. The proposed method shows excellent convergence and accuracy, which has been compared with the results of the existing literatures. Numerous new results for free vibration analysis of FG shallow shells with various boundary conditions, geometric parameter, material parameters, gradient parameters, and volume distribution functions are investigated, which may serve as the benchmark solution for future researches.
\end{abstract}

\section{Introduction}

The functionally gradient material (FGM) can be got by making the material properties of the structures change continuously in the thickness direction. This can make it possible to weaken or eliminate the internal defect and improve the bearing capacity of the structure and environmental adaptability. As the basic structure, shallow shell is widely used in the fields of aeronautics, astronautics, ship engineering, petrochemical container, and civil engineering. In the application of engineering practice, the main body of structures is made up of plate, cylindrical shell, spherical shell, hyperbolic paraboloidal shell, and so on. Therefore, it is of great significance to establish a unified analytical model to study the free vibration, buckling, and postbuckling characteristics of FG double curved shallow shells.

The double curved shallow shell structures have many special forms. The plate is one of the special forms by setting the curvature of two directions to infinity. As the most common form, there have been many results of the research on FG plate. Matsunaga [1] analyzed the free vibration and buckling stresses of simply supported FG plates according to a 2D higher-order deformation theory (HSDT). Nguyen et al. [2] established a FSDT plate model to study a simply supported square plate and a cylindrical bending sandwich plate clamped at both ends. Zhao et al. [3, 4] employed FSDT to investigate the free vibration and buckling analysis of FG plates on the basis of the element-free kp-Ritz method. Shen et al. $[5,6]$ investigated the nonlinear bending of simply supported FG plates reinforced by single-walled carbon nanotubes subjected to a transverse uniform or sinusoidal load in thermal environments based on a HSDT. Belabed et al. [7] obtained an efficient and simple higher-order shear and normal deformation theory for bending and free vibration analysis of simply supported FG plates. Neves et al. $[8,9]$ presented a quasi-3D sinusoidal shear deformation 
theory and quasi-3D HSDT for the static and free vibration and buckling analysis of FG plates by applying Carrera's unified formulation and meshless technique. Tounsi et al. [10] presented a refined trigonometric shear deformation theory (RTSDT) for the thermoelastic bending analysis of FG sandwich plates. Benachour et al. [11] used four-variable refined plate theory for free vibrations of FG clamped plates with arbitrary gradient based on Navier technique and Ritz method. Thai and Vo [12,13] developed a new sinusoidal shear deformation theory for bending, buckling, and vibration of simply supported FG plates. Although a lot of researches about the vibration characteristics of FG plates have been done, there are many limitations in these studies, such as the various boundary conditions, varying gradient parameters, and volume distribution functions.

The FG cylindrical shell can be seen as the single curved FG shallow shell. For this kind of cylindrical shell structure, the researches on the vibration characteristics have been very mature. Sheng and Wang $[14,15]$ investigated thermal vibration, buckling, and dynamic stability analysis of a FG cylindrical shell based on rotary inertia, FSDT, and modal expansion method. Vel [16] presented an exact elasticity solution for the free and forced vibration of simply supported FG cylindrical shells by using either the Mori-Tanaka method or asymptotic expansion homogenization (AEH) method. Shah et al. [17] studied the vibration behaviors of FG cylindrical shells on the Winkler and Pasternak foundations. Matsunaga [18] examined free vibration and stability of FG simply supported circular cylindrical shells by applying twodimensional HSDT. Zahedinejad et al. [19] proposed a semianalytical 3D free vibration analysis of functionally graded curved cylindrical panels with two opposite edges simply supported and arbitrary boundary conditions at the other edges based on the differential quadrature method (DQM). Santos et al. [20] developed a semi-analytical finite element model for the analysis of FG cylindrical shells by using the 3D linear elastic theory. Sepiani et al. [21] investigated vibration and buckling analysis of two-layered functionally graded cylindrical shell, considering the effects of transverse shear and rotary inertia based on FSDT and the classical shell theory (CST). Bagherizadeh et al. [22] studied the mechanical buckling of simply supported FG cylindrical shell on the Pasternak foundations based on HSDT. Beni et al. [23] analyzed the free vibration of size-dependent shear deformable simply supported FG cylindrical shell on the basis of FSDT and modified couple stress theory. From these results, it is not difficult to find that most of the boundary conditions of the cylindrical shell are simply supported boundary conditions or fixed boundary conditions. The effects of the elastic boundary conditions on the vibration are rarely mentioned.

As a kind of shallow shell structure with double curvature, some structural forms are often used in engineering practice, such as spherical shells, hyperbolic paraboloidal shell, and drum shell. It is not difficult to find that these structures can be obtained by changing the geometric parameters and the coordinates. Therefore, a unified analytical model is developed to study the vibration characteristics of varying FG shallow shell structures. Tornabene [24-26] focused on the free vibration and dynamic behavior of FG conical, cylindrical shells and annular plates with a four-parameter power-law distribution based on the 2D GDM and FSDT. Besides, Tornabene et al. [27] applied higher-order equivalent single layer theories to study free vibrations of free-form FG doubly curved shells. Neves et al. [28] applied radial basis functions collocation to examine the free vibration analysis of FG shells which included spherical as well as cylindrical shell panels with all edges clamped or simply supported based on HSDT. Pradyumna et al. [29] carried out free vibration analysis of FG curved panels using a higher-order finite element formulation. Matsunaga [30] analyzed natural frequencies and buckling stresses of FG shallow shells based on 2D HSDT. Three types of simply supported shallow shells with positive, zero, and negative Gaussian curvature were considered. Alijani et al. [31] investigated the nonlinear forced vibrations of simply supported FG doubly curved shallow shells based on Donnell's nonlinear shallow shell theory and the Galerkin method. Su et al. [32] presented a unified solution for vibration analysis of FG cylindrical, conical shells and annular plates with general boundary conditions by applying the FSDT and Rayleigh-Ritz procedure. Qu et al. [33] described a unified formulation for free, steady-state, and transient vibration analyses of FG shells with arbitrary boundary conditions on the basis of the FSDT. In this paper, the free vibrations of functionally graded cylindrical, conical, and spherical shells with different combinations of free, shear-diaphragm, simply supported, clamped, and elasticsupported boundary conditions were discussed. Alijani et al. [34] employed a pseudo-arclength continuation and collocation scheme to analyze thermal effects on nonlinear vibrations of simply supported FG doubly curved shells based on the HSDT. From the existing literatures, we can find that there have been a lot of discussions about the free vibration or buckling of the FG cylindrical shell, spherical shell, and conical shell. However, there are some limitations in the study of hyperbolic paraboloidal shell, which is a kind of the shallow shell structure. Moreover, the research on the multigradient parameters also has some limitations.

Stimulated by the restriction of the varying boundary conditions and establishment of unified model in the current literature researches, the free vibration analysis of the unified FG shallow shell with varying general boundary constraints is developed. Based on the FSDT, an improved Fourier series solution is extended, which is previously proposed by $\mathrm{Li}$ et al. $[35,36]$, to study the vibration of FG shallow shell with general boundary constraints. The five displacement functions are all written as a feasible superposition of the $2 \mathrm{D}$ trigonometric series expansion, ignoring the influence of boundary conditions, in spectral form, as a double Fourier cosine series and two supplementary functions. On the basis of the traditional Fourier series, these supplementary functions are added to eliminate the discontinuous or jumping phenomenon in the boundaries which are regarded as periodic functions and defined within the entire coordinates of FG shallow shells. All these unknown coefficients are defined in the generalized coordinates which can be solved by Rayleigh-Ritz procedure [37-40]. It is very easy to realize the change of different boundary conditions by changing the value of the five springs in the plate's four edges [41-45]. This 
method can realize parametric study without modifying the main program. Besides, the results obtained by the present method show good convergence and accuracy by being compared with those results obtained by literatures. It should be pointed out that the varying thickness has a great effect on the natural frequencies of the plates and shells. Many references have already been devoted to the study of the free vibration of multilayered plates [46-49] and shells [50-55] by using advanced analytical models based on variable throughthe-thickness kinematic. Therefore, in this paper, the effects of various thicknesses on the natural frequencies of the FG shallow shells are manifested in various aspect ratios, such as length-thickness ratios and width-thickness ratios. Besides, we also study the effect of the varying boundary constraints, four kinds of gradient parameters, two different volume distribution functions, and various geometric parameters on the free vibration of the FG shallow shells.

\section{Theoretical Formulations}

2.1. Description of the Model. As shown in Figure 1, a FG double curved shallow shell model is established to analyze the vibration characteristics. A coordinate system in the midsurface of the double curved shallow shell is established. In this coordinate system, $x, y$, and $z$ represent the length, width, and thickness directions. Besides, $a$ and $b$ are signed as the length along $x$ and $y$ directions and $h$ is the thickness of the $z$ direction. $R_{x}$ and $R_{y}$ are the radii of the curvature along $x$ and $y$ directions, respectively. An artificial spring technique is used to gain the vibration characteristics of FG shallow shell structures. Five types of springs are used to simulate the boundary conditions of the model, which are linear springs $\left(k_{u}, k_{v}, k_{w}\right)$ and rotational springs $\left(K_{x}, K_{y}\right)$, respectively. Different boundary conditions can be realized by setting different stiffness values of the springs. For instance, the fixed support can be easily gained when the spring coefficients on the four edges are infinity which is set to $1 E 15$ in the numerical calculation.

Figure 2 shows the various studied FG shallow shells which are used to validate the accuracy and versatility of the proposed method. It should be pointed out that we can easily obtain a rectangular plate structure by setting the $R_{x}=$ $R_{y}=\infty$, as shown in Figure 2(a). The cylindrical shell can be gained when $R_{x}=\infty, R_{\beta}=R$, as the model in Figure 2(c). The spherical shell and hyperbolic paraboloidal shell can be obtained when $R_{x}=R_{y}=R$ and $R_{x}=-R_{y}=R$ as shown in Figures 2(b) and 2(d).

2.2. Admissible Displacement Functions. In order to eliminate the discontinuous or jumping phenomenon in the boundaries of FG shallow shells with arbitrary elastic supports, we propose an IFMS to express the displacement and rotation functions [59-61] which can be regarded as periodic functions:

$$
\begin{gathered}
u_{0}(x, y, t)=e^{-j \omega t}\left\{\sum_{m=0}^{+\infty} \sum_{n=0}^{+\infty} A_{m n}^{1} \cos \left(\lambda_{m} x\right) \cos \left(\lambda_{n} y\right)\right. \\
+\sum_{m=-2} \sum_{n=0}^{+\infty} A_{m n}^{2} \sin \left(\lambda_{m} x\right) \cos \left(\lambda_{n} y\right)
\end{gathered}
$$

$$
\begin{aligned}
& \left.+\sum_{n=-2}^{-1} \sum_{m=0}^{+\infty} A_{m n}^{3} \cos \left(\lambda_{m} x\right) \sin \left(\lambda_{n} y\right)\right\} \\
& v_{0}(x, y, t)=e^{-j \omega t}\left\{\sum_{m=0}^{+\infty} \sum_{n=0}^{+\infty} B_{m n}^{1} \cos \left(\lambda_{m} x\right) \cos \left(\lambda_{n} y\right)\right. \\
& +\sum_{m=-2}^{-1} \sum_{n=0}^{+\infty} B_{m n}^{2} \sin \left(\lambda_{m} x\right) \cos \left(\lambda_{n} y\right) \\
& \left.+\sum_{n=-2}^{-1} \sum_{m=0}^{+\infty} B_{m n}^{3} \cos \left(\lambda_{m} x\right) \sin \left(\lambda_{n} y\right)\right\} \\
& w_{0}(x, y, t)=e^{-j \omega t}\left\{\sum_{m=0}^{+\infty} \sum_{n=0}^{+\infty} C_{m n}^{4} \cos \left(\lambda_{m} x\right) \cos \left(\lambda_{n} y\right)\right. \\
& +\sum_{m=-2}^{-1} \sum_{n=0}^{+\infty} C_{m n}^{2} \sin \left(\lambda_{m} x\right) \cos \left(\lambda_{n} y\right) \\
& \left.+\sum_{n=-2}^{-1} \sum_{m=0}^{+\infty} C_{m n}^{3} \cos \left(\lambda_{m} x\right) \sin \left(\lambda_{n} y\right)\right\} \\
& \varphi_{x}(x, y, t)=e^{-j \omega t}\left\{\sum_{m=0}^{+\infty} \sum_{n=0}^{+\infty} D_{m n}^{1} \cos \left(\lambda_{m} x\right) \cos \left(\lambda_{n} y\right)\right. \\
& +\sum_{m=-2}^{-1} \sum_{n=0}^{+\infty} D_{m n}^{2} \sin \left(\lambda_{m} x\right) \cos \left(\lambda_{n} y\right) \\
& \left.+\sum_{n=-2}^{-1} \sum_{m=0}^{+\infty} D_{m n}^{3} \cos \left(\lambda_{m} x\right) \sin \left(\lambda_{n} y\right)\right\} \\
& \varphi_{y}(x, y, t)=e^{-j \omega t}\left\{\sum_{m=0}^{+\infty} \sum_{n=0}^{+\infty} E_{m n}^{1} \cos \left(\lambda_{m} x\right) \cos \left(\lambda_{n} y\right)\right. \\
& +\sum_{m=-2}^{-1} \sum_{n=0}^{+\infty} E_{m n}^{2} \sin \left(\lambda_{m} x\right) \cos \left(\lambda_{n} y\right) \\
& \left.+\sum_{n=-2}^{-1} \sum_{m=0}^{+\infty} E_{m n}^{3} \cos \left(\lambda_{m} x\right) \sin \left(\lambda_{n} y\right)\right\}
\end{aligned}
$$

in which $\lambda_{m}=m \pi / a, \lambda_{n}=n \pi / b$. The unknown $2 \mathrm{D}$ Fourier coefficients expansions are $A_{m n}^{i}, B_{m n}^{i}, C_{m n}^{i}, D_{m n}^{i}$, and $E_{m n}^{i}(i=$ $1,2,3)$, respectively.

2.3. Kinematic Relations and Stress Resultants. The displacement of previously mentioned FG shallow shell model can be expressed according to the displacements and rotations of the middle surface $[62,63]$, which is based on the theory of the FSDT.

$$
\begin{aligned}
U(x, y, t) & =u_{0}(x, y, t)+z \varphi_{x}(x, y, t) \\
V(x, y, t) & =v_{0}(x, y, t)+z \varphi_{y}(x, y, t) \\
W(x, y, t) & =w_{0}(x, y, t),
\end{aligned}
$$




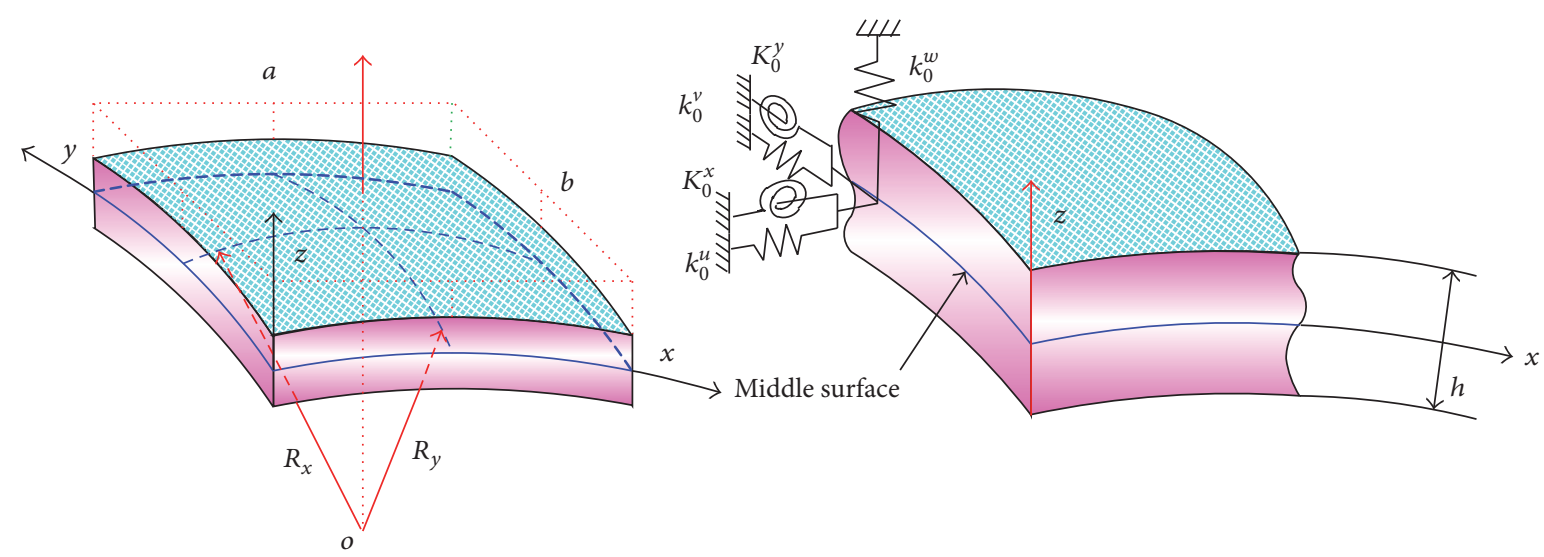

FIGURE 1: Geometric parameters and coordinate system of FG shallow shell with elastic boundary conditions.

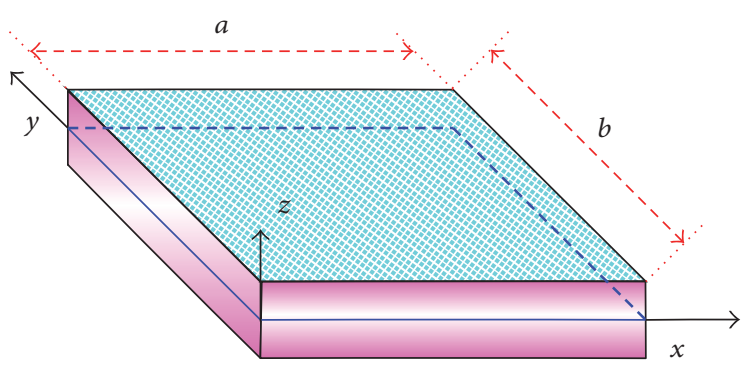

(a) Plate

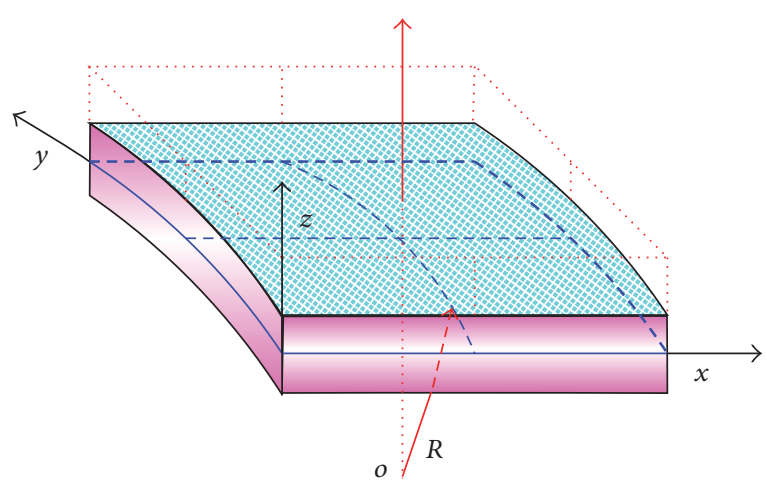

(c) Cylindrical shell

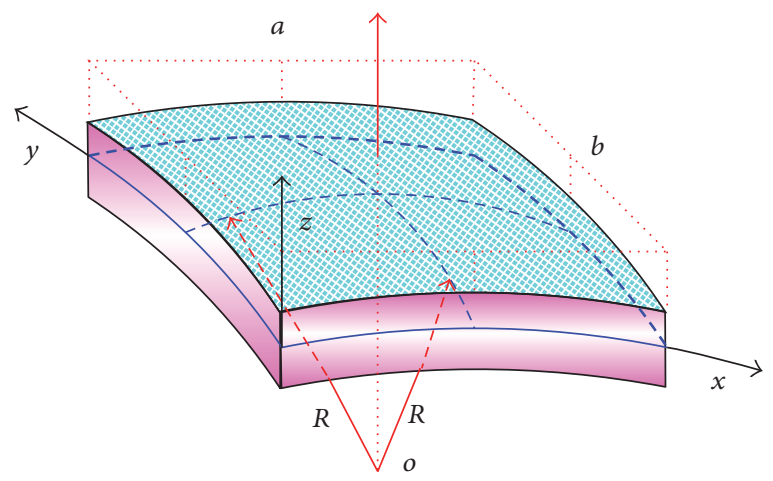

(b) Spherical shell

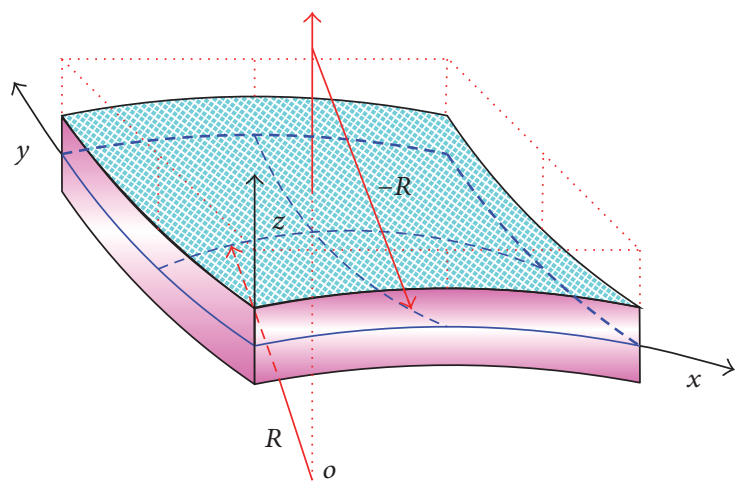

(d) Hyperbolic paraboloidal shell

FIGURE 2: FG shallow shells with various structure types: (a) plate; (b) spherical shell; (c) cylindrical shell; (d) hyperbolic paraboloidal shell.

where $t$ is the time variable. Then $u_{0}, v_{0}$, and $w_{0}$ represent the middle surface displacements in $x, y$, and $z$ direction, and the rotations of transverse normal for $x$ - and $y$-axes are denoted by $\varphi_{x}$ and $\varphi_{y}$, respectively. According to the small deformation elasticity theory and linear strains-displacement relations, the relationship of strain-stress can be expressed as

$$
\begin{aligned}
& \varepsilon_{x x}=\varepsilon_{x x}^{0}+z \chi_{x x}, \\
& \varepsilon_{y y}=\varepsilon_{y y}^{0}+z \chi_{y y},
\end{aligned}
$$

$$
\begin{aligned}
& \gamma_{y z}=\gamma_{y z}^{0}, \\
& \gamma_{x z}=\gamma_{x z}^{0}, \\
& \gamma_{x y}=\gamma_{x y}^{0}+z \chi_{x y},
\end{aligned}
$$

where $\varepsilon_{x x}^{0}, \varepsilon_{x x}^{0}$, and $\gamma_{x y}^{0}$ denote the symbols of the normal and shear strains and $\chi_{x x}, \chi_{y y}$, and $\chi_{x y}$ express curvature and twist changes. Transverse shear strains $\left(\gamma_{x z}, \gamma_{y z}\right)$ are regarded as 
constant, ignoring the thickness change. These corresponding quantities can be written as

$$
\begin{aligned}
& \varepsilon_{x x}^{0}=\frac{\partial u_{0}}{\partial x}+\frac{w_{0}}{R_{x}}, \\
& \gamma_{x z}^{0}=\frac{\partial w_{0}}{\partial x}+\varphi_{x}-\frac{u}{R_{x}} \\
& \chi_{x x}=\frac{\partial \varphi_{x}}{\partial x}, \\
& \varepsilon_{y y}^{0}=\frac{\partial v_{0}}{\partial y}+\frac{w_{0}}{R_{y}}, \\
& \gamma_{y z}^{0}=\frac{\partial w_{0}}{\partial y}+\varphi_{y}-\frac{v_{0}}{R_{y}} \\
& \chi_{y y}=\frac{\partial \varphi_{y}}{\partial y}, \\
& \gamma_{x y}^{0}=\frac{\partial u_{0}}{\partial y}+\frac{\partial v_{0}}{\partial x} \\
& \chi_{x y}=\frac{\partial \varphi_{x}}{\partial y}+\frac{\partial \varphi_{y}}{\partial x} .
\end{aligned}
$$

Based on the generalized Hooke's law, the relationship between stress and strain can be obtained by

$$
\begin{aligned}
& \left\{\begin{array}{l}
\sigma_{x x} \\
\sigma_{y y} \\
\tau_{x y}
\end{array}\right\}=\left[\begin{array}{ccc}
Q_{11} & Q_{12} & 0 \\
Q_{12} & Q_{11} & 0 \\
0 & 0 & Q_{66}
\end{array}\right]\left\{\begin{array}{l}
\varepsilon_{x x} \\
\left.\varepsilon_{y y}\right\} \\
\gamma_{x y}
\end{array}\right\}, \\
& \left\{\begin{array}{c}
\tau_{x z} \\
\tau_{y z}
\end{array}\right\}=\left[\begin{array}{cc}
Q_{66} & 0 \\
0 & Q_{66}
\end{array}\right]\left\{\begin{array}{l}
\gamma_{x z} \\
\gamma_{y z}
\end{array}\right\},
\end{aligned}
$$

where the normal stresses are $\sigma_{x x}$ and $\sigma_{y y}$, shear stresses are $\tau_{x z}, \tau_{y z}$, and $\tau_{x y}$, and $Q_{e f}(e, f=1,2,6)$ represent the material coefficients which can be solved as follows:

$$
\begin{aligned}
& Q_{11}=\frac{E(z)}{1-\mu^{2}(z)}, \\
& Q_{12}=\frac{\mu(z) E(z)}{1-\mu^{2}(z)}, \\
& Q_{66}=\frac{E(z)}{2[1+\mu(z)]} .
\end{aligned}
$$

Young's modulus, density, and Poisson's ratio are $E(z)$, $\rho(z)$, and $\mu(z)$ which can be expressed as functions in the thickness direction.

$$
\begin{aligned}
& E(z)=\left(E_{C}-E_{S}\right) V_{C}+E_{S} \\
& \rho(z)=\left(\rho_{C}-\rho_{S}\right) V_{C}+\rho_{S} \\
& \mu(z)=\left(\mu_{C}-\mu_{S}\right) V_{C}+\mu_{S}
\end{aligned}
$$

in which $C$ and $S$ represent the two different material constituents which show smooth and continuous mechanical behavior. Here, the volume fraction $\left(V_{C}\right)$ will be represented by two general types of volume distribution function based on the four gradient parameters $(i, j, c, p)$.

$$
\begin{gathered}
\operatorname{FGM}_{\mathrm{I}(i / j / c / p)}: V_{C}=\left[1-i\left(\frac{1}{2}+\frac{z}{h}\right)+j\left(\frac{1}{2}+\frac{z}{h}\right)^{c}\right]^{p} \\
\mathrm{FGM}_{\mathrm{II}(i / j / c / p)}: V_{C} \\
=\left[1-i\left(\frac{1}{2}-\frac{z}{h}\right)+j\left(\frac{1}{2}-\frac{z}{h}\right)^{c}\right]^{p},
\end{gathered}
$$

where $i, j$, and $c$ determine the variation of the material in the thickness direction and $p$ is the gradient power-law exponent which can only take the positive. When the value of $p$ is infinite, the structure of $\mathrm{FGM}_{\mathrm{I}}$ is composed of the pure $C$ material, but the structure of $\mathrm{FGM}_{\mathrm{II}}$ is composed of the pure $S$ material. When the value of $p$ is 0 , the material of structure is exactly the opposite. This relationship of volume fractions should be met as $V_{C}+V_{S}=1$.

The constitutive equation of force and moment contacted with strain can be expressed as

$$
\begin{gathered}
{\left[\begin{array}{c}
N_{x} \\
N_{y} \\
N_{x y} \\
M_{x} \\
M_{y} \\
M_{x y}
\end{array}\right]=\left[\begin{array}{cccccc}
A_{11} & A_{12} & 0 & B_{11} & B_{12} & 0 \\
A_{12} & A_{11} & 0 & B_{12} & B_{11} & 0 \\
0 & 0 & A_{66} & 0 & 0 & B_{66} \\
B_{11} & B_{12} & 0 & D_{11} & D_{12} & 0 \\
B_{12} & B_{11} & 0 & D_{12} & D_{11} & 0 \\
0 & 0 & B_{66} & 0 & 0 & D_{66}
\end{array}\right]\left[\begin{array}{c}
\varepsilon_{x x}^{0} \\
\varepsilon_{y y}^{0} \\
\gamma_{x y}^{0} \\
\chi_{x x} \\
\chi_{y y} \\
\chi_{x y}
\end{array}\right],} \\
{\left[\begin{array}{l}
Q_{x} \\
Q_{y}
\end{array}\right]=\kappa_{c}\left[\begin{array}{cc}
A_{66} & 0 \\
0 & A_{66}
\end{array}\right]\left[\begin{array}{l}
\gamma_{x z} \\
\gamma_{y z}
\end{array}\right],}
\end{gathered}
$$

where the stress $\left(N_{x}, N_{y}\right)$, shear force $\left(N_{x y}\right)$, torque $\left(M_{x}, M_{y}\right)$, torsional moment $\left(M_{x y}\right)$, and transverse shear force $\left(Q_{x}, Q_{y}\right)$ resultants can be obtained by establishing the relationship with strains. Besides, the shear correction factor is $K_{c}$ which is generally set to $5 / 6$. The extensional, extensional-bending, and bending stiffness coefficients are $A_{e f}, B_{e f}$, and $D_{e f}$ which can be gained by the integration over the thickness:

$$
\left(A_{e f}, B_{e f}, D_{e f}\right)=\int_{-h / 2}^{h / 2} Q_{e f}(z)\left(1, z, z^{2}\right) d z .
$$

Through the derivation of the formula, we can establish the relationship between internal force and kinematics of the provided FG shallow shell model.

2.4. Energy Expressions. As mentioned earlier, the main work of our study is the free vibration characteristics of FG shallow shell with elastic supports. Thus, we study the FG shallow shell vibrations based on Rayleigh-Ritz energy method [6467] which can obtain more accurate results. The Lagrangian energy function for the shallow shell can be written as

$$
L=T-U_{\text {shell }}-U_{\text {springs }} .
$$


The total kinetic energy $T$ of the FG shallow shell is written as

$$
\begin{aligned}
T & =\frac{1}{2} \int_{0}^{a} \int_{0}^{b}\left\{I_{0}\left[\left(\frac{\partial u_{0}}{\partial t}\right)^{2}+\left(\frac{\partial v_{0}}{\partial t}\right)^{2}+\left(\frac{\partial w_{0}}{\partial t}\right)^{2}\right]\right. \\
& +2 I_{1}\left(\frac{\partial u_{0}}{\partial t} \frac{\partial \varphi_{x}}{\partial t}+\frac{\partial v_{0}}{\partial t} \frac{\partial \varphi_{y}}{\partial t}\right) \\
& \left.+I_{2}\left[\left(\frac{\partial \varphi_{x}}{\partial t}\right)^{2}+\left(\frac{\partial \psi_{y}}{\partial t}\right)^{2}\right]\right\} d y d x,
\end{aligned}
$$

where $I_{0}, I_{1}$, and $I_{2}$ are expressed as

$$
\left(\begin{array}{lll}
I_{0} & I_{1} & I_{2}
\end{array}\right)=\int_{-h / 2}^{h / 2} \rho(z)\left(1, z^{1}, z^{2}\right) d z
$$

$U$ is the strain energy stored inside the FG shallow shell:

$$
\begin{gathered}
U_{\text {shell }}=\frac{1}{2} \int_{0}^{a} \int_{0}^{b}\left\{N_{x} \varepsilon_{x x}^{0}+N_{y} \varepsilon_{y y}^{0}+N_{x y} \varepsilon_{x y}^{0}+M_{x} \chi_{x x}\right. \\
\left.+M_{y} \chi_{y y}+M_{x y} \chi_{x y}+Q_{x} \gamma_{x z}+Q_{y} \gamma_{y z}\right\} d y d x
\end{gathered}
$$

By combining (4), (9), and (14) together, we can divide the strain energy formula into three parts, which can be rewritten as $U_{\text {shell }}=U_{s}+U_{b}+U_{b s}$. In this expression, $U_{s}, U_{b}$, and $U_{b s}$ are stretching energy, bending energy, and bending-stretching coupling energy which can be expressed as follows:

$$
\begin{aligned}
U_{s} & =\frac{1}{2} \int_{0}^{a} \int_{0}^{b}\left\{A_{11}\left(\frac{\partial u_{0}}{\partial x}+\frac{w_{0}}{R_{x}}\right)^{2}+A_{11}\left(\frac{\partial v_{0}}{\partial y}+\frac{w_{0}}{R_{y}}\right)^{2}\right. \\
& +2 A_{12}\left(\frac{\partial u_{0}}{\partial x}+\frac{w_{0}}{R_{x}}\right)\left(\frac{\partial v_{0}}{\partial y}+\frac{w_{0}}{R_{y}}\right)
\end{aligned}
$$

$$
\begin{aligned}
& +A_{66}\left(\frac{\partial u_{0}}{\partial y}+\frac{\partial v_{0}}{\partial x}\right)^{2}+\kappa_{c} A_{66}\left(\frac{\partial w_{0}}{\partial x}+\varphi_{x}-\frac{u_{0}}{R_{x}}\right)^{2} \\
& \left.+\kappa_{c} A_{66}\left(\frac{\partial w_{0}}{\partial y}+\varphi_{y}-\frac{v_{0}}{R_{y}}\right)^{2}\right\} d y d x
\end{aligned}
$$

$$
\begin{aligned}
U_{b} & =\frac{1}{2} \int_{0}^{a} \int_{0}^{b}\left\{D_{11}\left(\frac{\partial \varphi_{x}}{\partial x}\right)^{2}+D_{11}\left(\frac{\partial \varphi_{y}}{\partial y}\right)^{2}\right. \\
& +2 D_{12}\left(\frac{\partial \varphi_{x}}{\partial x}\right)\left(\frac{\partial \varphi_{y}}{\partial y}\right) \\
& \left.+D_{66}\left(\frac{\partial \varphi_{x}}{\partial y}+\frac{\partial \varphi_{y}}{\partial x}\right)^{2}\right\} d y d x
\end{aligned}
$$

$$
\begin{aligned}
U_{b s} & =\int_{0}^{a} \int_{0}^{b}\left\{B_{11}\left(\frac{\partial u_{0}}{\partial x}+\frac{w_{0}}{R_{x}}\right)\left(\frac{\partial \varphi_{x}}{\partial x}\right)\right. \\
& +B_{12}\left[\left(\frac{\partial u_{0}}{\partial x}+\frac{w_{0}}{R_{x}}\right)\left(\frac{\partial \varphi_{y}}{\partial y}\right)+\left(\frac{\partial v_{0}}{\partial y}+\frac{w_{0}}{R_{y}}\right)\left(\frac{\partial \varphi_{x}}{\partial x}\right)\right] \\
& +B_{11}\left(\frac{\partial v_{0}}{\partial y}+\frac{w_{0}}{R_{y}}\right)\left(\frac{\partial \varphi_{y}}{\partial y}\right) \\
& \left.+B_{66}\left(\frac{\partial v_{0}}{\partial x}+\frac{\partial u_{0}}{\partial y}\right)\left(\frac{\partial \varphi_{x}}{\partial y}+\frac{\partial \varphi_{y}}{\partial x}\right)\right\} d y d x
\end{aligned}
$$

For the arbitrary elastic-supported case, the potential energy with the five kinds of restrained springs [68-74], which is the simulation of boundary conditions, should be written as

$$
\begin{aligned}
& U_{\text {springs }}=\frac{1}{2} \int_{0}^{b} \int_{-h / 2}^{h / 2}\left\{\left[k_{x 0}^{u} u_{0}(x, y)^{2}+k_{x 0}^{v} v_{0}(x, y)^{2}+k_{x 0}^{w} w_{0}(x, y)^{2}+K_{x 0}^{x} \varphi_{x}(x, y)^{2}+K_{x 0}^{y} \varphi_{y}(x, y)^{2}\right]_{x=0}\right. \\
& \left.+\left[k_{x a}^{u} u_{0}(x, y)^{2}+k_{x a}^{v} v_{0}(x, y)^{2}+k_{x a}^{w} w_{0}(x, y)^{2}+K_{x a}^{x} \varphi_{x}(x, y)^{2}+K_{x a}^{y} \varphi_{y}(x, y)^{2}\right]_{x=a}\right\} d z d y+\frac{1}{2} \\
& \quad \cdot \int_{0}^{a} \int_{-h / 2}^{h / 2}\left\{\left[k_{y 0}^{u} u_{0}(x, y)^{2}+k_{y 0}^{v} v_{0}(x, y)^{2}+k_{y 0}^{w} w_{0}(x, y)^{2}+K_{y 0}^{x} \varphi_{x}(x, y)^{2}+K_{y 0}^{y} \varphi_{y}(x, y)^{2}\right]_{y=0}\right. \\
& \left.+\left[k_{y b}^{u} u_{0}(x, y)^{2}+k_{y b}^{v} v_{0}(x, y)^{2}+k_{y b}^{w} w_{0}(x, y)^{2}+K_{y b}^{x} \varphi_{x}(x, y)^{2}+K_{y b}^{y} \varphi_{y}(x, y)^{2}\right]_{y=b}\right\} d z d x
\end{aligned}
$$

2.5. Equation Solving. Partial derivative of unknown coefficients by Lagrange equation $L$ is zero based on the RayleighRitz technology [75-78]. Therefore, a matrix form can be obtained by substituting (1a)-(1e) into (11)-(16), which can be written as

$$
\left(\mathbf{K}-\omega^{2} \mathbf{M}\right) \mathbf{G}=\mathbf{0},
$$

where the stiffness and mass matrixes for the FGM shallow shell are denoted by $\mathbf{K}$ and $\mathbf{M}$. The unknown Fourier coefficients can be expressed as a vector in the form of

$$
\mathbf{G}=\left[\begin{array}{lllll}
\mathbf{G}_{u_{0}} & \mathbf{G}_{v_{0}} & \mathbf{G}_{w_{0}} & \mathbf{G}_{\varphi_{x}} & \mathbf{G}_{\varphi_{y}}
\end{array}\right]^{\mathrm{T}}
$$

So far, the natural frequencies and coefficients $\mathbf{G}$ can be easily got by solving the eigenvalues and eigenvectors of a 
TABLE 1: Spring stiffness values for the various boundary conditions of FGM shallow shell.

\begin{tabular}{|c|c|c|c|c|c|c|}
\hline \multirow{2}{*}{ Edges } & \multirow{2}{*}{$\mathrm{BC}$} & \multicolumn{5}{|c|}{ Spring stiffness values } \\
\hline & & $k_{u}$ & $k_{v}$ & $k_{w}$ & $K_{x}$ & $K_{y}$ \\
\hline \multirow{6}{*}{$x=0 / x=a$} & $\mathrm{~F}$ & 0 & 0 & 0 & 0 & 0 \\
\hline & $\mathrm{C}$ & $10^{15}$ & $10^{15}$ & $10^{15}$ & $10^{15}$ & $10^{15}$ \\
\hline & $S$ & 0 & $10^{15}$ & $10^{15}$ & 0 & $10^{15}$ \\
\hline & $\mathrm{E}^{1}$ & $10^{8}$ & $10^{15}$ & $10^{15}$ & $10^{15}$ & $10^{15}$ \\
\hline & $E^{2}$ & $10^{8}$ & $10^{8}$ & $10^{15}$ & $10^{15}$ & $10^{15}$ \\
\hline & $E^{3}$ & $10^{8}$ & $10^{8}$ & $10^{8}$ & $10^{15}$ & $10^{15}$ \\
\hline \multirow{6}{*}{$y=0 / y=b$} & $\mathrm{~F}$ & 0 & 0 & 0 & 0 & 0 \\
\hline & $\mathrm{C}$ & $10^{15}$ & $10^{15}$ & $10^{15}$ & $10^{15}$ & $10^{15}$ \\
\hline & S & $10^{15}$ & 0 & $10^{15}$ & $10^{15}$ & 0 \\
\hline & $E^{1}$ & $10^{15}$ & $10^{8}$ & $10^{15}$ & $10^{15}$ & $10^{15}$ \\
\hline & $\mathrm{E}^{2}$ & $10^{8}$ & $10^{8}$ & $10^{15}$ & $10^{15}$ & $10^{15}$ \\
\hline & $\mathrm{E}^{3}$ & $10^{8}$ & $10^{8}$ & $10^{8}$ & $10^{15}$ & $10^{15}$ \\
\hline
\end{tabular}

standard matrix in (18). Substitute G into (1a)-(1e) and get the specific displacement expressions of the FG shallow shell. Then, the corresponding mode shape can be immediately obtained.

\section{Numerical Results and Discussion}

In this part, a number of examples for the different FG shallow shells with varying elastic boundary conditions will be discussed. In the numerical calculation, the fast convergence of this method is proved by setting different truncation value of the displacement function expressions. By comparing with the available results extracted from the existing literatures, it proves the accuracy of the proposed method and model in this paper. It should be noted that the frequency parameters used in this paper are $\Omega=\omega a^{2} / h /\left(\rho_{c} / E_{c}\right)^{1 / 2}$. In order to facilitate the description, this paper uses alphabetic strings to represent the boundary constraints (BC). For example, SCFE represents a kind of boundary constraints by setting the spring values of the four edges to the numbers shown in Table 1. Specifically, $S$ is simply supported, $C$ is clamped edge, $F$ is free edge, and $E$ is elastic support. Besides, the material properties involved in this paper are presented here, and we will not give special explanation anymore in the following example:

$$
\begin{aligned}
& \mathrm{Al}: E=70 \mathrm{GPa} ; \mu=0.3 ; \rho=2707 \mathrm{~kg} / \mathrm{m}^{3} \\
& \mathrm{Al}_{2} \mathrm{O}_{3}: E=380 \mathrm{GPa} ; \mu=0.3 ; \rho=3800 \mathrm{~kg} / \mathrm{m}^{3} \\
& \mathrm{ZrO}_{2}: E=151 \mathrm{GPa} ; \mu=0.3 ; \rho=3000 \mathrm{~kg} / \mathrm{m}^{3} .
\end{aligned}
$$

3.1. Convergence Study. As previously mentioned in (1a)-(1e), we can get the convergence criterion by the truncation value of $M$ and $N$ in the displacement function expressions in the numerical calculation. Therefore, the values of $M$ and $N$ are the direct representation of the convergence for the proposed method. In Table 2, we can get the convergence of first eight frequency parameters $\Omega$ for the various shallow shells structures with SSSS boundary constraints whose functionally graded material is $\mathrm{Al} / \mathrm{Al}_{2} \mathrm{O}_{3}$. Their geometrical dimensions are $a / b=1, h / a=0.1$, and $R=1 \mathrm{~m}$.

The method presented in this paper shows fast convergence which can be found in Table 1. For example, the biggest difference for the worst case of the plate which is made by the contrast of $8 \times 8$ and $18 \times 18$ is less than $0.02 \%$. It is not difficult to find that the biggest difference for the contrast of $8 \times 8$ and $18 \times 18$ of the cylindrical shell is also less than $0.02 \%$. Besides, for the spherical shell and hyperbolic paraboloidal shell, the biggest difference between these two truncated values is $0.017 \%$ and $0.019 \%$. Through these results, we can find that the method shows good uniform convergence for different structures which shows the accuracy of the unified model. In addition, it is necessary to point out that, in order to make the results obtained in the following numerical examples more accurate, we use the invariant truncation values of $M=N=$ 14.

3.2. Validation and Some New Results. In this section, the accuracy of the proposed method is verified by being compared with the literature results. In addition, this paper also gives some new results, which can provide a benchmark for the future research. The first five frequency parameters $\Omega$ for $\mathrm{Al} / \mathrm{Al}_{2} \mathrm{O}_{3}$ square plate with SSSS boundary constraints and varying length-thickness ratios $a / h$ and gradient power-law exponent parameter $p$ are given in Table 3. The geometric parameters are $a=b=1 \mathrm{~m}$ and the material parameters of alumina and aluminum have been given previously. The results of the present method are compared with those of Jin et al. [56] which show good agreement. From Table 3, we can easily find that the frequency parameter $\Omega$ of the square plate is decreasing gradually with the increase of $a / h$ and $p$. In Table 4 , the first frequency parameters $\Omega$ for $\mathrm{Al} / \mathrm{ZrO} 2$ plate with various boundary constraints are given. The influence of different length-width ratio $a / b$, thickness-width ratio $h / b$, and gradient power-law exponent parameter $p$ on the plate frequency is also discussed. The results of the free vibration under SSSS boundary conditions are compared with those of Kiani et al. [57], which show good agreement. It is worth 
TABLE 2: Convergence of frequency parameter $\Omega$ for $\mathrm{Al} / \mathrm{Al}_{2} \mathrm{O}_{3}$ shallow shells with SSSS boundary constraints $\left(\mathrm{FGM}_{\mathrm{I}(i=1 / j=0 / c / p=1)}, R=1\right.$, $a / b=1, h=0.1)$.

\begin{tabular}{|c|c|c|c|c|c|c|c|c|c|}
\hline \multirow{2}{*}{ Type } & \multirow{2}{*}{$M \times N$} & \multicolumn{8}{|c|}{ Mode number } \\
\hline & & 1 & 2 & 3 & 4 & 5 & 6 & 7 & 8 \\
\hline \multirow{6}{*}{ Plate } & $8 \times 8$ & 4.417 & 10.585 & 10.585 & 16.195 & 16.195 & 16.303 & 19.910 & 19.910 \\
\hline & $10 \times 10$ & 4.417 & 10.585 & 10.585 & 16.195 & 16.195 & 16.303 & 19.908 & 19.908 \\
\hline & $12 \times 12$ & 4.417 & 10.585 & 10.585 & 16.195 & 16.195 & 16.303 & 19.907 & 19.907 \\
\hline & $14 \times 14$ & 4.417 & 10.585 & 10.585 & 16.195 & 16.195 & 16.303 & 19.906 & 19.906 \\
\hline & $16 \times 16$ & 4.417 & 10.585 & 10.585 & 16.195 & 16.195 & 16.303 & 19.906 & 19.906 \\
\hline & $18 \times 18$ & 4.417 & 10.585 & 10.585 & 16.195 & 16.195 & 16.303 & 19.906 & 19.906 \\
\hline \multirow{6}{*}{ Cylindrical shell } & $8 \times 8$ & 5.739 & 10.493 & 12.308 & 16.053 & 16.195 & 16.613 & 19.880 & 21.162 \\
\hline & $10 \times 10$ & 5.739 & 10.493 & 12.308 & 16.053 & 16.195 & 16.613 & 19.877 & 21.159 \\
\hline & $12 \times 12$ & 5.739 & 10.493 & 12.308 & 16.053 & 16.195 & 16.613 & 19.877 & 21.159 \\
\hline & $14 \times 14$ & 5.739 & 10.493 & 12.308 & 16.053 & 16.195 & 16.613 & 19.876 & 21.158 \\
\hline & $16 \times 16$ & 5.739 & 10.493 & 12.308 & 16.053 & 16.195 & 16.613 & 19.876 & 21.158 \\
\hline & $18 \times 18$ & 5.739 & 10.493 & 12.308 & 16.053 & 16.195 & 16.613 & 19.876 & 21.158 \\
\hline \multirow{6}{*}{ Spherical shell } & $8 \times 8$ & 8.946 & 13.139 & 13.139 & 16.053 & 16.053 & 18.082 & 21.422 & 21.422 \\
\hline & $10 \times 10$ & 8.946 & 13.139 & 13.139 & 16.053 & 16.053 & 18.082 & 21.419 & 21.419 \\
\hline & $12 \times 12$ & 8.946 & 13.139 & 13.139 & 16.053 & 16.053 & 18.082 & 21.419 & 21.419 \\
\hline & $14 \times 14$ & 8.946 & 13.139 & 13.139 & 16.053 & 16.053 & 18.082 & 21.418 & 21.418 \\
\hline & $16 \times 16$ & 8.946 & 13.139 & 13.139 & 16.053 & 16.053 & 18.082 & 21.418 & 21.418 \\
\hline & $18 \times 18$ & 8.946 & 13.139 & 13.139 & 16.053 & 16.053 & 18.082 & 21.418 & 21.418 \\
\hline \multirow{6}{*}{ Hyperbolic paraboloidal shell } & $8 \times 8$ & 3.609 & 10.940 & 11.121 & 15.434 & 16.053 & 16.334 & 20.271 & 20.706 \\
\hline & $10 \times 10$ & 3.609 & 10.940 & 11.121 & 15.434 & 16.053 & 16.334 & 20.269 & 20.703 \\
\hline & $12 \times 12$ & 3.609 & 10.940 & 11.121 & 15.434 & 16.053 & 16.334 & 20.268 & 20.703 \\
\hline & $14 \times 14$ & 3.609 & 10.940 & 11.121 & 15.434 & 16.053 & 16.334 & 20.268 & 20.702 \\
\hline & $16 \times 16$ & 3.609 & 10.940 & 11.121 & 15.434 & 16.053 & 16.334 & 20.268 & 20.702 \\
\hline & $18 \times 18$ & 3.609 & 10.940 & 11.121 & 15.434 & 16.053 & 16.334 & 20.268 & 20.702 \\
\hline
\end{tabular}

TABLE 3: Frequency parameters $\Omega$ for $\mathrm{Al} / \mathrm{Al}_{2} \mathrm{O}_{3}$ square plate with SSSS boundary constraints, varying geometric parameters, and gradient power-law exponent $p\left(\mathrm{FGM}_{\mathrm{I}(i=1 / j=0 / c / p)}\right)$.

\begin{tabular}{|c|c|c|c|c|c|c|c|}
\hline \multirow{2}{*}{$h / a$} & \multirow{2}{*}{$p$} & \multirow{2}{*}{ Method } & \multicolumn{5}{|c|}{ Mode number } \\
\hline & & & 1 & 2 & 3 & 4 & 5 \\
\hline \multirow{6}{*}{0.1} & \multirow{2}{*}{0} & Present & 5.769 & 13.76 & 13.76 & 19.48 & 19.48 \\
\hline & & [56] & 5.779 & 13.81 & 13.81 & 19.48 & 19.48 \\
\hline & \multirow{2}{*}{1} & Present & 4.417 & 10.59 & 10.59 & 16.19 & 16.19 \\
\hline & & [56] & 4.428 & 10.63 & 10.63 & 16.20 & 16.20 \\
\hline & \multirow{2}{*}{5} & Present & 3.785 & 9.004 & 9.004 & 12.63 & 12.63 \\
\hline & & [56] & 3.774 & 8.931 & 8.931 & 12.64 & 12.64 \\
\hline \multirow{6}{*}{0.2} & \multirow{2}{*}{0} & Present & 5.280 & 9.741 & 9.741 & 11.55 & 11.55 \\
\hline & & [56] & 5.304 & 9.742 & 9.742 & 11.65 & 11.65 \\
\hline & \multirow{2}{*}{1} & Present & 4.076 & 8.086 & 8.086 & 9.005 & 9.005 \\
\hline & & [56] & 4.100 & 8.089 & 8.089 & 9.108 & 9.108 \\
\hline & \multirow{2}{*}{5} & Present & 3.447 & 6.297 & 6.297 & 7.496 & 7.496 \\
\hline & & [56] & 3.405 & 6.296 & 6.296 & 7.344 & 7.344 \\
\hline
\end{tabular}


TABLE 4: Frequency parameters $\Omega$ for $\mathrm{Al} / \mathrm{ZrO}_{2}$ plate with various boundary constraints, varying geometric parameters, and gradient powerlaw exponent $p\left(\mathrm{FGM}_{\mathrm{II}(i=1 / j=0 / c / p)}\right)$.

\begin{tabular}{|c|c|c|c|c|c|c|c|c|c|c|}
\hline $\mathrm{BC}$ & $a / b$ & $h / b$ & Method & $p=0$ & $p=0.5$ & $p=1$ & $p=2$ & $p=5$ & $p=10$ & $p=\infty$ \\
\hline \multirow{6}{*}{ SSSS } & \multirow{4}{*}{1} & \multirow{2}{*}{0.1} & Present & 5.7693 & 5.1932 & 4.9504 & 4.7750 & 4.6315 & 4.5071 & 4.1352 \\
\hline & & & [57] & 5.7693 & 5.1932 & 4.9504 & 4.7750 & 4.6315 & 4.5071 & 4.1353 \\
\hline & & \multirow{2}{*}{0.02} & Present & 5.9647 & 5.3631 & 5.1135 & 4.9382 & 4.7988 & 4.6710 & 4.2753 \\
\hline & & & [57] & 5.9647 & 5.3631 & 5.1135 & 4.9382 & 4.7988 & 4.6710 & 4.2753 \\
\hline & 2 & 0.1 & Present & 14.6070 & 13.1429 & 12.5296 & 12.0910 & 11.7358 & 11.4215 & 10.4698 \\
\hline & & 0.02 & Present & 14.9198 & 13.4149 & 12.7906 & 12.3523 & 12.0040 & 11.6844 & 10.6940 \\
\hline \multirow{4}{*}{ СССС } & \multirow{2}{*}{1} & 0.1 & Present & 9.8425 & 8.8831 & 8.4665 & 8.1474 & 7.8691 & 7.6511 & 7.0548 \\
\hline & & 0.02 & Present & 10.8410 & 9.7492 & 9.2954 & 8.9754 & 8.7198 & 8.4872 & 7.7705 \\
\hline & \multirow{2}{*}{2} & 0.1 & Present & 27.5886 & 24.8797 & 23.7153 & 22.8390 & 22.0870 & 21.4798 & 19.7746 \\
\hline & & 0.02 & Present & 29.6598 & 26.6713 & 25.4299 & 24.5558 & 23.8588 & 23.2228 & 21.2592 \\
\hline \multirow{4}{*}{ CSCS } & \multirow{2}{*}{1} & 0.1 & Present & 8.0703 & 7.2786 & 6.9375 & 6.6802 & 6.4591 & 6.2816 & 5.7845 \\
\hline & & 0.02 & Present & 8.7301 & 7.8505 & 7.4851 & 7.2277 & 7.0225 & 6.8352 & 6.2574 \\
\hline & \multirow{2}{*}{2} & 0.1 & Present & 16.0659 & 14.4609 & 13.7857 & 13.2987 & 12.9004 & 12.5534 & 11.5155 \\
\hline & & 0.02 & Present & 16.5502 & 14.8811 & 14.1886 & 13.7021 & 13.3152 & 12.9606 & 11.8626 \\
\hline \multirow{4}{*}{$\mathrm{E}^{1} \mathrm{E}^{2} \mathrm{E}^{1} \mathrm{E}^{2}$} & \multirow{2}{*}{1} & 0.1 & Present & 1.6260 & 1.6528 & 1.6666 & 1.6807 & 1.6951 & 1.7018 & 1.7098 \\
\hline & & 0.02 & Present & 10.8410 & 9.7492 & 9.2954 & 8.9754 & 8.7198 & 8.4872 & 7.7705 \\
\hline & \multirow{2}{*}{2} & 0.1 & Present & 5.6307 & 5.7230 & 5.7706 & 5.8192 & 5.8686 & 5.8913 & 5.9186 \\
\hline & & 0.02 & Present & 29.6598 & 26.6713 & 25.4299 & 24.5559 & 23.8588 & 23.2228 & 21.2592 \\
\hline \multirow{4}{*}{$E^{2} E^{3} E^{2} E^{3}$} & \multirow{2}{*}{1} & 0.1 & Present & 1.6249 & 1.6514 & 1.6651 & 1.6790 & 1.6931 & 1.6995 & 1.7073 \\
\hline & & 0.02 & Present & 10.4114 & 9.4120 & 8.9917 & 8.6918 & 8.4499 & 8.2330 & 7.5680 \\
\hline & \multirow{2}{*}{2} & 0.1 & Present & 5.6174 & 5.7067 & 5.7522 & 5.7982 & 5.8442 & 5.8650 & 5.8896 \\
\hline & & 0.02 & Present & 27.4294 & 25.0188 & 23.9872 & 23.2505 & 22.6568 & 22.1105 & 20.3974 \\
\hline
\end{tabular}

noting that these results in Table 4 are consistent with the results obtained in Table 3.

Cylindrical shell, as a special form of shallow shell with double curvature, is well known and widely used in engineering practice. The free vibration characteristics of FG cylindrical shells are studied based on the unified doubly curved shallow shell model established in this paper. Table 5 gives the first nine frequencies of $\mathrm{FGM}_{\mathrm{I}(i=1 / j=0 / c / p)}$ cylindrical shell with FFCF boundary constraints and varying gradient parameter of power-law exponent $p$. There are two kinds of functionally graded materials whose properties are $E_{c}=168 \mathrm{GPa}, E_{m}=$ $70 \mathrm{GPa}, \mu_{c}=\mu_{m}=0.3, p_{c}=5700 \mathrm{~kg} / \mathrm{m}^{3}, p_{m}=2707 \mathrm{~kg} / \mathrm{m}^{3}$. The geometric parameters of cylindrical shell are $h=0.1 \mathrm{~m}$, $R=1 \mathrm{~m}, a=2 \mathrm{~m}, b=2 \pi / 3 \mathrm{~m}$. The first frequency parameter $\Omega$ for $\mathrm{Al} / \mathrm{ZrO}_{2}$ cylindrical shell with SSSS boundary constraints is given in Table 6 . At the same time, the effects of various geometric parameters, including length-thickness ratio $a / h$ and radius-length ratio $R / a$, and power-law exponent $p$ are also discussed. The accuracy of the results is verified by being compared with the related references $[26,57,58]$. As shown in Tables 5 and 6 , the frequency of the cylindrical shell is reduced gradually when the radius $R$, the thickness $h$, or the gradient power-law exponent $p$ increase. In Table 7, we give the first-order frequency parameter $\Omega$ of free vibration of $\mathrm{Al} / \mathrm{Al}_{2} \mathrm{O}_{3}$ cylindrical shells with different boundary conditions and varying geometric parameters of $a / h$ and $h / b$. In the studied cylindrical shell model, the radius is $R=2 \mathrm{~m}$. In this table, the effects of two general types of volume distribution function $\left(\mathrm{FGM}_{\mathrm{I}(i=1 / j=0 / c / p=1)}\right.$ and $\left.\mathrm{FGM}_{\mathrm{II}(i=1 / j=0 / c / p=1)}\right)$ on the frequency of cylindrical shells are also given. It should be pointed out that the frequencies of the cylindrical shell under $\mathrm{FGM}_{\mathrm{I}}$ and $\mathrm{FGM}_{\mathrm{II}}$ have some small changes when the shell has the same boundary conditions and geometric parameters.

The first frequency parameter $\Omega$ of $\mathrm{Al} / \mathrm{ZrO}_{2}$ spherical shell with SSSS boundary constraints is given in Table 8 . The effects of various geometric parameters, including lengththickness ratio $a / h$ and radius-length ratio $R / a$, and powerlaw exponent $p$ are also discussed in this table. It shows good agreement when the results obtained by the proposed method are compared with those results obtained by Kiani [57]. We can find that, with the radius increasing, the frequency of the spherical shell decreases when other parameters remain unchanged. Some new results are given in Table 9. In this table, we give the first-order frequency parameter $\Omega$ of the free vibration of $\mathrm{Al} / \mathrm{Al}_{2} \mathrm{O}_{3}$ spherical shell with varying boundary conditions and geometric parameters $(a / h, h / b)$. Geometry parameters of this spherical shell are radius $R=$ $2 \mathrm{~m}$ and $b=1 \mathrm{~m}$, respectively. Under the two general types of volume distribution function of $\mathrm{FGM}_{\mathrm{I}}$ and $\mathrm{FGM}_{\mathrm{II}}$, the firstorder frequency of free vibration of spherical shell is given in Table 9. The frequencies of the spherical shell under FGM and $\mathrm{FGM}_{\mathrm{II}}$ have some small changes which has the same laws shown in Table 7. For the free vibration of this FG spherical shell, it is significant to study the change of natural frequency under different boundary constraints.

As mentioned earlier, the hyperbolic shell is a special form which can be obtained by setting the radius of curvature as $R_{x}=-R_{y}=R$. It should be noted here that the plate 
TABLE 5: Frequencies $(\mathrm{Hz})$ of $\mathrm{FGM}_{\mathrm{I}(i=1 / j=0 / c / p)}$ cylindrical shell with FFCF boundary constraints and varying gradient power-law exponent $p$ $\left(E_{c}=168 \mathrm{GPa}, E_{m}=70 \mathrm{GPa}, \mu_{c}=\mu_{m}=0.3, p_{c}=5700 \mathrm{~kg} / \mathrm{m}^{3}, p_{m}=2707 \mathrm{~kg} / \mathrm{m}^{3}, h=0.1, R=1, a=2, b=2 \pi / 3\right)$.

\begin{tabular}{|c|c|c|c|c|c|c|c|c|c|c|}
\hline \multirow{2}{*}{$p$} & \multirow{2}{*}{ Method } & \multicolumn{9}{|c|}{ Mode number } \\
\hline & & 1 & 2 & 3 & 4 & 5 & 6 & 7 & 8 & 9 \\
\hline \multirow{3}{*}{0} & Present & 61.03 & 94.83 & 153.13 & 241.67 & 276.26 & 291.68 & 355.13 & 450.74 & 512.49 \\
\hline & [58] & 61.02 & 94.82 & 153.13 & 241.39 & 275.83 & 291.45 & 355.14 & 450.76 & 511.92 \\
\hline & {$[26]$} & 61.06 & 94.92 & 153.11 & 241.75 & 276.37 & 291.94 & 355.07 & 450.82 & 512.48 \\
\hline \multirow{3}{*}{0.6} & Present & 59.11 & 92.94 & 148.16 & 234.52 & 266.87 & 287.37 & 342.44 & 442.01 & 495.33 \\
\hline & [58] & 59.24 & 93.14 & 148.51 & 234.79 & 267.06 & 287.85 & 343.22 & 443.06 & 495.89 \\
\hline & [26] & 59.13 & 93.03 & 148.14 & 234.60 & 266.97 & 287.63 & 342.38 & 442.09 & 495.31 \\
\hline \multirow{3}{*}{1} & Present & 58.79 & 92.39 & 147.51 & 233.23 & 265.51 & 285.52 & 341.09 & 439.41 & 492.81 \\
\hline & [58] & 58.96 & 92.65 & 147.94 & 233.64 & 265.86 & 286.16 & 342.08 & 440.72 & 493.67 \\
\hline & [26] & 58.82 & 92.48 & 147.49 & 233.31 & 265.61 & 285.77 & 341.04 & 439.49 & 492.80 \\
\hline \multirow{3}{*}{5} & Present & 59.93 & 91.45 & 151.59 & 236.35 & 272.08 & 278.81 & 353.89 & 435.11 & 504.54 \\
\hline & [58] & 60.09 & 91.69 & 152.02 & 236.75 & 272.42 & 279.34 & 354.89 & 436.34 & 505.35 \\
\hline & [26] & 59.96 & 91.54 & 151.57 & 236.42 & 272.19 & 279.06 & 353.83 & 435.18 & 504.56 \\
\hline \multirow{3}{*}{20} & Present & 59.13 & 90.21 & 149.31 & 233.26 & 268.47 & 275.15 & 348.37 & 429.12 & 497.85 \\
\hline & [58] & 59.19 & 90.29 & 149.49 & 233.27 & 268.37 & 275.23 & 348.80 & 429.63 & 497.87 \\
\hline & [26] & 59.16 & 90.30 & 149.29 & 233.32 & 268.57 & 275.41 & 348.32 & 429.19 & 497.87 \\
\hline \multirow{3}{*}{50} & Present & 58.18 & 89.52 & 146.47 & 229.93 & 263.84 & 274.07 & 340.84 & 425.59 & 489.36 \\
\hline & [58] & 58.20 & 89.55 & 146.55 & 229.79 & 263.58 & 273.98 & 341.04 & 425.83 & 489.06 \\
\hline & {$[26]$} & 58.21 & 89.60 & 146.45 & 230.00 & 263.95 & 274.32 & 340.79 & 425.66 & 489.36 \\
\hline \multirow{3}{*}{100} & Present & 57.72 & 89.21 & 145.09 & 228.32 & 261.56 & 273.66 & 337.14 & 424.02 & 485.17 \\
\hline & [58] & 57.73 & 89.21 & 145.14 & 228.12 & 261.23 & 273.51 & 337.25 & 424.15 & 484.75 \\
\hline & [26] & 57.75 & 89.29 & 145.08 & 228.39 & 261.66 & 273.90 & 337.09 & 424.10 & 485.16 \\
\hline \multirow{3}{*}{$\infty$} & Present & 57.17 & 88.83 & 143.43 & 226.37 & 258.77 & 273.21 & 332.64 & 422.20 & 480.04 \\
\hline & [58] & 57.16 & 88.81 & 143.43 & 226.11 & 258.36 & 273.00 & 332.65 & 422.21 & 479.49 \\
\hline & [26] & 57.19 & 88.91 & 143.41 & 226.44 & 258.87 & 273.46 & 332.59 & 422.27 & 480.02 \\
\hline
\end{tabular}

and the hyperbolic paraboloidal shell are all about the symmetrical distribution of the middle surface. So, for the two kinds of structural distribution of FGM $\mathrm{F}_{\mathrm{I}}$ and $\mathrm{FGM}_{\mathrm{II}}$, the frequencies for free vibration of the plate and the hyperbolic paraboloidal shell have no difference. Therefore, the following research does not distinguish under the two general types of volume distribution function. Table 10 gives the first-order frequency of the $\mathrm{Al} / \mathrm{ZrO}_{2}$ hyperbolic paraboloidal shell with $\mathrm{E}^{1} \mathrm{E}^{2} \mathrm{E}^{1} \mathrm{E}^{2}$ boundary constraints. The geometry parameter is set as $a=b=1 \mathrm{~m}$. With the increase of gradient power-law exponent parameter $p$, the frequency decreases gradually. Furthermore, the increase of radius and thickness leads to the decrease of frequency. In Table 11, the first three frequency parameters $\Omega$ of $\mathrm{Al} / \mathrm{Al}_{2} \mathrm{O}_{3}$ hyperbolic paraboloidal shell with different boundary constraints and varying geometric parameters $(a / b, h / b)$ are given. In this table, the radius remains constant and is set to $R=2 \mathrm{~m}$. It is easy to see from the table that the boundary conditions have a great influence on the frequency for the free vibration of the FG hyperbolic paraboloidal shell. There is an interesting phenomenon that the increase of thickness-width ratio $h / b$ has little effect on the natural frequency. But the length-width ratio $a / b$ has a great influence on the frequency; that is, the frequency increases with the increase of $a / b$.

3.3. Parametric Study. In this section, the free vibration characteristics of FG shallow shells are studied by using the four kinds of special structures with varying boundary constraints and gradient power-law exponent parameter $p$. In order to compare conveniently, this section uses $\mathrm{Al} / \mathrm{Al}_{2} \mathrm{O}_{3}$ as the function gradient material, and its volume distribution functions are all FGM . $_{\text {. }}$

Firstly, the effect of gradient power-law exponent parameter $p$ on the vibration characteristics of the $\mathrm{Al} / \mathrm{Al}_{2} \mathrm{O}_{3}$ shallow shells is studied. Figure 3 shows the first-order natural frequency parameters $\Omega$ for the free vibration of plate, cylindrical shell, spherical shell, and hyperbolic paraboloidal shell with varying power-law exponent $p$ and six kinds of boundary constraints. In this case, the geometrical dimensions are $a / b=1, h / b=0.05$, and $R=2 \mathrm{~m}$. It can be seen from Figure 3 that, under different boundary conditions, the effects of the function gradient power-law exponent parameter $p$ on the vibration characteristics of the shells cannot give a definite conclusion easily. The effects of different 
TABLE 6: Frequency parameters $\Omega$ for $\mathrm{Al} / \mathrm{ZrO}_{2}$ cylindrical shell with SSSS boundary constraints and varying geometric parameters and gradient power-law exponent $p\left(\mathrm{FGM}_{\mathrm{II}(i=1 / j=0 / c / p)}, a / b=1\right)$.

\begin{tabular}{|c|c|c|c|c|c|c|c|c|c|}
\hline$a / h$ & $R / a$ & Method & $p=0$ & $p=0.5$ & $p=1$ & $p=2$ & $p=5$ & $p=10$ & $p=\infty$ \\
\hline \multirow{12}{*}{10} & \multirow{2}{*}{2} & Present & 6.1667 & 5.5612 & 5.2958 & 5.0890 & 4.9112 & 4.7782 & 4.4201 \\
\hline & & [57] & 6.1552 & 5.5522 & 5.2876 & 5.0812 & 4.9032 & 4.7700 & 4.4119 \\
\hline & \multirow{2}{*}{3} & Present & 5.9510 & 5.3592 & 5.1052 & 4.9150 & 4.7563 & 4.6288 & 4.2655 \\
\hline & & [57] & 5.9456 & 5.3548 & 5.1012 & 4.9111 & 4.7524 & 4.6249 & 4.2616 \\
\hline & \multirow{2}{*}{5} & Present & 5.8357 & 5.2521 & 5.0046 & 4.8235 & 4.6749 & 4.5501 & 4.1829 \\
\hline & & [57] & 5.8337 & 5.2504 & 5.0031 & 4.8220 & 4.6734 & 4.5486 & 4.1814 \\
\hline & \multirow{2}{*}{10} & Present & 5.7860 & 5.2069 & 4.9625 & 4.7856 & 4.6411 & 4.5170 & 4.1472 \\
\hline & & {$[57]$} & 5.7855 & 5.2065 & 4.9622 & 4.7852 & 4.6407 & 4.5166 & 4.1469 \\
\hline & \multirow{2}{*}{20} & Present & 5.7735 & 5.1960 & 4.9527 & 4.7768 & 4.6333 & 4.5091 & 4.1382 \\
\hline & & [57] & 5.7734 & 5.1959 & 4.9526 & 4.7767 & 4.6332 & 4.5090 & 4.1382 \\
\hline & \multirow{2}{*}{100} & Present & 5.7695 & 5.1931 & 4.9503 & 4.7748 & 4.6314 & 4.5070 & 4.1354 \\
\hline & & [57] & 5.7695 & 5.1931 & 4.9503 & 4.7748 & 4.6314 & 4.5070 & 4.1354 \\
\hline \multirow{12}{*}{50} & \multirow{2}{*}{2} & Present & 13.6959 & 12.5601 & 11.9594 & 11.3453 & 10.6948 & 10.3516 & 9.8168 \\
\hline & & {$[57]$} & 13.6904 & 12.5575 & 11.9578 & 11.3440 & 10.6928 & 10.3488 & 9.8128 \\
\hline & \multirow{2}{*}{3} & Present & 10.1888 & 9.3097 & 8.8667 & 8.4394 & 8.0024 & 7.7542 & 7.3030 \\
\hline & & [57] & 10.1854 & 9.3077 & 8.8651 & 8.4379 & 8.0006 & 7.7522 & 7.3006 \\
\hline & \multirow{2}{*}{5} & Present & 7.7632 & 7.0509 & 6.7181 & 6.4289 & 6.1535 & 5.9732 & 5.5644 \\
\hline & & [57] & 7.7616 & 7.0497 & 6.7171 & 6.4280 & 6.1525 & 5.9721 & 5.5633 \\
\hline & \multirow{2}{*}{10} & Present & 6.4625 & 5.8318 & 5.5589 & 5.3505 & 5.1714 & 5.0289 & 4.6321 \\
\hline & & [57] & 6.4620 & 5.8314 & 5.5586 & 5.3502 & 5.1711 & 5.0285 & 4.6317 \\
\hline & \multirow{2}{*}{20} & Present & 6.0930 & 5.4840 & 5.2283 & 5.0443 & 4.8945 & 4.7630 & 4.3673 \\
\hline & & [57] & 6.0929 & 5.4839 & 5.2282 & 5.0442 & 4.8944 & 4.7629 & 4.3672 \\
\hline & \multirow{2}{*}{100} & Present & 5.9699 & 5.3680 & 5.1181 & 4.9424 & 4.8026 & 4.6747 & 4.2790 \\
\hline & & [57] & 5.9699 & 5.3680 & 5.1181 & 4.9424 & 4.8026 & 4.6747 & 4.2790 \\
\hline
\end{tabular}

TABLE 7: Frequency parameters $\Omega$ for $\mathrm{Al} / \mathrm{Al}_{2} \mathrm{O}_{3}$ cylindrical shell with different $\mathrm{BC}$ and varying geometric parameters.

\begin{tabular}{|c|c|c|c|c|c|c|c|c|c|c|}
\hline \multirow{2}{*}{ Material type } & \multirow{2}{*}{$a / b$} & \multirow{2}{*}{$h / b$} & \multicolumn{8}{|c|}{$\mathrm{BC}$} \\
\hline & & & SSSS & $\mathrm{SE}^{1} \mathrm{SE}^{1}$ & SCSC & CFCF & $\mathrm{CE}^{2} \mathrm{CE}^{2}$ & CCCC & $E^{1} E^{2} E^{1} E^{2}$ & $\mathrm{E}^{3} \mathrm{FE}^{3} \mathrm{~F}$ \\
\hline \multirow{6}{*}{$\mathrm{FGM}_{\mathrm{I}(i=1 / j=0 / c / p=1)}$} & \multirow{3}{*}{1} & 0.1 & 4.812 & 6.428 & 7.204 & 5.027 & 7.734 & 8.446 & 1.108 & 0.777 \\
\hline & & 0.05 & 6.059 & 7.610 & 9.742 & 5.882 & 8.864 & 10.908 & 3.132 & 2.097 \\
\hline & & 0.01 & 14.011 & 17.976 & 22.193 & 8.862 & 19.552 & 23.812 & 17.424 & 7.511 \\
\hline & \multirow{3}{*}{2} & 0.1 & 11.358 & 20.257 & 25.185 & 5.600 & 20.933 & 25.740 & 3.838 & 2.085 \\
\hline & & 0.05 & 12.807 & 21.974 & 35.872 & 7.241 & 22.612 & 36.379 & 10.845 & 4.570 \\
\hline & & 0.01 & 34.617 & 43.664 & 65.965 & 12.143 & 43.049 & 68.030 & 35.525 & 10.029 \\
\hline \multirow{6}{*}{$\mathrm{FGM}_{\mathrm{II}(i=1 / j=0 / c / p=1)}$} & \multirow{3}{*}{1} & 0.1 & 4.766 & 6.357 & 7.144 & 5.032 & 7.653 & 8.393 & 1.108 & 0.777 \\
\hline & & 0.05 & 6.034 & 7.568 & 9.707 & 5.887 & 8.816 & 10.876 & 3.132 & 2.097 \\
\hline & & 0.01 & 13.992 & 17.949 & 22.166 & 8.863 & 19.524 & 23.783 & 17.410 & 7.512 \\
\hline & \multirow{3}{*}{2} & 0.1 & 11.190 & 19.946 & 24.954 & 5.603 & 20.604 & 25.517 & 3.838 & 2.085 \\
\hline & & 0.05 & 12.720 & 21.796 & 35.747 & 7.244 & 22.425 & 36.257 & 10.845 & 4.571 \\
\hline & & 0.01 & 34.589 & 43.622 & 65.857 & 12.143 & 43.005 & 67.921 & 35.484 & 10.028 \\
\hline
\end{tabular}


TABLE 8: Frequency parameters $\Omega$ for $\mathrm{Al} / \mathrm{ZrO}_{2}$ spherical shell with SSSS boundary constraints, varying geometric parameters, and gradient power-law exponent $p\left(\mathrm{FGM}_{\mathrm{II}(i=1 / j=0 / c / p)}\right)$.

\begin{tabular}{|c|c|c|c|c|c|c|c|c|c|}
\hline$a / h$ & $R / a$ & Method & $p=0$ & $p=0.5$ & $p=1$ & $p=2$ & $p=5$ & $p=10$ & $p=\infty$ \\
\hline \multirow{12}{*}{10} & \multirow{2}{*}{2} & Present & 7.4580 & 6.7593 & 6.4304 & 6.1422 & 5.8730 & 5.7072 & 5.3457 \\
\hline & & [57] & 7.4599 & 6.7612 & 6.4322 & 6.1440 & 5.8747 & 5.7088 & 5.4370 \\
\hline & \multirow{2}{*}{3} & Present & 6.5826 & 5.9454 & 5.6595 & 5.4275 & 5.2222 & 5.0792 & 4.7182 \\
\hline & & [57] & 6.5834 & 5.9462 & 5.6603 & 5.4283 & 5.2230 & 5.0798 & 4.7186 \\
\hline & \multirow{2}{*}{5} & Present & 6.0765 & 5.4745 & 5.2142 & 5.0165 & 4.8500 & 4.7197 & 4.3554 \\
\hline & & [57] & 6.0767 & 5.4748 & 5.2145 & 5.0168 & 4.8503 & 4.7200 & 4.3556 \\
\hline & \multirow{2}{*}{10} & Present & 5.8478 & 5.2629 & 5.0149 & 4.8335 & 4.6846 & 4.5595 & 4.1915 \\
\hline & & {$[57]$} & 5.8479 & 5.2630 & 5.0150 & 4.8336 & 4.6847 & 4.5596 & 4.1915 \\
\hline & \multirow{2}{*}{20} & Present & 5.7891 & 5.2096 & 4.9651 & 4.7881 & 4.6435 & 4.5193 & 4.1494 \\
\hline & & [57] & 5.7891 & 5.2096 & 4.9651 & 4.7881 & 4.6336 & 4.5194 & 4.1494 \\
\hline & \multirow{2}{*}{100} & Present & 5.7701 & 5.1935 & 4.9505 & 4.7750 & 4.6316 & 4.5073 & 4.1358 \\
\hline & & [57] & 5.7701 & 5.1935 & 4.9505 & 4.7750 & 4.6316 & 4.5073 & 4.1358 \\
\hline \multirow{12}{*}{50} & \multirow{2}{*}{2} & Present & 25.3976 & 23.3588 & 22.2354 & 21.0343 & 19.7303 & 19.0801 & 18.2042 \\
\hline & & [57] & 25.3980 & 23.3591 & 22.2357 & 21.0345 & 19.7305 & 19.0803 & 18.2044 \\
\hline & \multirow{2}{*}{3} & Present & 17.5981 & 16.1645 & 15.3894 & 14.5770 & 13.7045 & 13.2582 & 12.6137 \\
\hline & & [57] & 17.5982 & 16.1646 & 15.3895 & 14.5771 & 13.7046 & 13.2583 & 12.6138 \\
\hline & \multirow{2}{*}{5} & Present & 11.6130 & 10.6300 & 10.1229 & 9.6194 & 9.0953 & 8.8085 & 8.3238 \\
\hline & & [57] & 11.6130 & 10.6300 & 10.1230 & 9.6194 & 9.0953 & 8.8086 & 8.3238 \\
\hline & \multirow{2}{*}{10} & Present & 7.7757 & 7.0622 & 6.7288 & 6.4393 & 6.1635 & 5.9830 & 5.5734 \\
\hline & & [57] & 7.7758 & 7.0621 & 6.7288 & 6.4393 & 6.1635 & 5.9830 & 5.5734 \\
\hline & \multirow{2}{*}{20} & Present & 6.4655 & 5.8346 & 5.5615 & 5.3531 & 5.1738 & 5.0313 & 4.6342 \\
\hline & & [57] & 6.4655 & 5.8345 & 5.5615 & 5.3531 & 5.1739 & 5.0313 & 4.6342 \\
\hline & \multirow{2}{*}{100} & Present & 5.9855 & 5.3827 & 5.1321 & 4.9553 & 4.8143 & 4.6859 & 4.2902 \\
\hline & & [57] & 5.9855 & 5.3827 & 5.1321 & 4.9553 & 4.8143 & 4.6859 & 4.2902 \\
\hline
\end{tabular}

TABLE 9: Frequency parameters $\Omega$ for $\mathrm{Al} / \mathrm{Al}_{2} \mathrm{O}_{3}$ spherical shell with different $\mathrm{BC}$ and varying geometric parameters.

\begin{tabular}{|c|c|c|c|c|c|c|c|c|c|c|}
\hline \multirow{2}{*}{ Material type } & \multirow{2}{*}{$a / b$} & \multirow{2}{*}{$h / b$} & \multicolumn{8}{|c|}{$\mathrm{BC}$} \\
\hline & & & SSSS & $\mathrm{SE}^{1} \mathrm{SE}^{1}$ & SCSC & CFCF & $\mathrm{CE}^{2} \mathrm{CE}^{2}$ & СССС & $E^{1} E^{2} E^{1} E^{2}$ & $\mathrm{E}^{3} \mathrm{FE}^{3} \mathrm{~F}$ \\
\hline \multirow{6}{*}{$\mathrm{FGM}_{\mathrm{I}(i=1 / j=0 / c / p=5)}$} & \multirow{3}{*}{1} & 0.1 & 4.925 & 6.125 & 6.409 & 5.055 & 7.243 & 7.894 & 1.322 & 0.822 \\
\hline & & 0.05 & 7.477 & 8.481 & 9.196 & 7.285 & 9.747 & 11.361 & 3.415 & 2.159 \\
\hline & & 0.01 & 32.351 & 32.787 & 34.926 & 17.654 & 33.135 & 37.776 & 24.646 & 7.302 \\
\hline & \multirow{3}{*}{2} & 0.1 & 15.821 & 21.297 & 24.259 & 11.287 & 20.579 & 25.672 & 4.597 & 2.176 \\
\hline & & 0.05 & 27.257 & 31.297 & 36.784 & 13.356 & 30.304 & 39.615 & 11.859 & 4.494 \\
\hline & & 0.01 & 128.022 & 130.877 & 139.230 & 25.017 & 96.411 & 141.174 & 83.190 & 15.355 \\
\hline \multirow{6}{*}{$\mathrm{FGM}_{\mathrm{II}(i=1 / j=0 / c / p=5)}$} & \multirow{3}{*}{1} & 0.1 & 4.811 & 5.978 & 6.271 & 5.008 & 7.079 & 7.773 & 1.335 & 0.822 \\
\hline & & 0.05 & 7.403 & 8.388 & 9.109 & 7.268 & 9.643 & 11.283 & 3.435 & 2.155 \\
\hline & & 0.01 & 32.298 & 32.732 & 34.864 & 17.628 & 33.064 & 37.709 & 24.590 & 7.294 \\
\hline & \multirow{3}{*}{2} & 0.1 & 15.500 & 20.813 & 23.870 & 11.219 & 20.774 & 25.311 & 4.643 & 2.167 \\
\hline & & 0.05 & 27.018 & 30.980 & 36.437 & 13.223 & 29.965 & 39.262 & 11.929 & 4.466 \\
\hline & & 0.01 & 127.816 & 130.666 & 138.997 & 24.983 & 96.203 & 140.922 & 83.010 & 15.328 \\
\hline
\end{tabular}


TABLE 10: Frequency parameters $\Omega$ for $\mathrm{Al} / \mathrm{ZrO}_{2}$ hyperbolic paraboloidal shell with $\mathrm{E}^{1} \mathrm{E}^{2} \mathrm{E}^{1} \mathrm{E}^{2}$ boundary constraints, varying geometric parameters, and gradient power-law exponent $p(a=b=1,(i=1 / j=0 / c / p))$.

\begin{tabular}{|c|c|c|c|c|c|c|c|c|}
\hline$a / h$ & $R / a$ & $p=0$ & $p=0.5$ & $p=1$ & $p=2$ & $p=5$ & $p=10$ & $p=\infty$ \\
\hline \multirow{7}{*}{10} & 1 & 2.493 & 2.378 & 2.328 & 2.289 & 2.256 & 2.234 & 2.182 \\
\hline & 2 & 1.879 & 1.859 & 1.852 & 1.849 & 1.849 & 1.847 & 1.839 \\
\hline & 3 & 1.743 & 1.747 & 1.750 & 1.756 & 1.764 & 1.767 & 1.768 \\
\hline & 5 & 1.669 & 1.687 & 1.697 & 1.708 & 1.720 & 1.725 & 1.731 \\
\hline & 10 & 1.637 & 1.661 & 1.674 & 1.687 & 1.701 & 1.707 & 1.715 \\
\hline & 20 & 1.629 & 1.655 & 1.668 & 1.682 & 1.696 & 1.703 & 1.711 \\
\hline & 100 & 1.626 & 1.653 & 1.667 & 1.681 & 1.695 & 1.702 & 1.710 \\
\hline \multirow{7}{*}{50} & 1 & 12.492 & 11.762 & 11.461 & 11.240 & 11.054 & 10.902 & 10.479 \\
\hline & 2 & 11.500 & 10.511 & 10.097 & 9.795 & 9.545 & 9.333 & 8.719 \\
\hline & 3 & 11.170 & 10.126 & 9.689 & 9.376 & 9.120 & 8.897 & 8.230 \\
\hline & 5 & 10.968 & 9.893 & 9.446 & 9.127 & 8.871 & 8.642 & 7.944 \\
\hline & 10 & 10.874 & 9.786 & 9.334 & 9.014 & 8.758 & 8.527 & 7.815 \\
\hline & 20 & 10.849 & 9.759 & 9.305 & 8.985 & 8.730 & 8.497 & 7.782 \\
\hline & 100 & 10.841 & 9.750 & 9.296 & 8.976 & 8.720 & 8.488 & 7.771 \\
\hline
\end{tabular}

TABLE 11: Frequency parameters $\Omega$ for $\mathrm{Al} / \mathrm{Al}_{2} \mathrm{O}_{3}$ hyperbolic paraboloidal shell with different $\mathrm{BC}$ and varying geometric parameters $(R=2$, $(i=1 / j=0 / c / p=1))$.

\begin{tabular}{|c|c|c|c|c|c|c|c|c|c|}
\hline \multirow{2}{*}{$a / b$} & \multirow{2}{*}{$h / b$} & \multirow{2}{*}{ Mode number } & \multicolumn{7}{|c|}{$\mathrm{BC}$} \\
\hline & & & SCSC & $\mathrm{SE}^{2} \mathrm{SE}^{2}$ & $\mathrm{CE}^{3} \mathrm{CE}^{3}$ & $E^{1} E^{1} E^{1} E^{1}$ & $E^{2} E^{2} E^{2} E^{2}$ & $E^{3} E^{3} E^{3} E^{3}$ & $E^{2} E^{3} E^{2} E^{3}$ \\
\hline \multirow{9}{*}{1} & \multirow{3}{*}{0.1} & 1 & 7.169 & 0.964 & 6.901 & 7.231 & 1.331 & 1.096 & 1.289 \\
\hline & & 2 & 11.951 & 5.898 & 8.566 & 14.497 & 1.339 & 1.096 & 1.314 \\
\hline & & 3 & 13.929 & 11.471 & 12.740 & 14.603 & 1.897 & 1.101 & 1.892 \\
\hline & \multirow{3}{*}{0.05} & 1 & 9.850 & 2.359 & 10.023 & 7.846 & 3.284 & 2.994 & 3.266 \\
\hline & & 2 & 14.100 & 6.290 & 12.273 & 16.727 & 3.296 & 3.096 & 3.274 \\
\hline & & 3 & 16.185 & 12.807 & 16.240 & 16.805 & 4.689 & 3.096 & 4.688 \\
\hline & \multirow{3}{*}{0.01} & 1 & 30.627 & 8.835 & 31.145 & 11.946 & 11.195 & 11.109 & 11.165 \\
\hline & & 2 & 32.776 & 21.977 & 31.649 & 25.687 & 25.177 & 23.159 & 23.378 \\
\hline & & 3 & 32.924 & 24.532 & 34.702 & 30.369 & 25.363 & 23.169 & 24.899 \\
\hline \multirow{9}{*}{2} & \multirow{3}{*}{0.1} & 1 & 26.447 & 3.857 & 16.542 & 22.198 & 4.566 & 3.730 & 4.257 \\
\hline & & 2 & 28.675 & 18.452 & 18.734 & 25.895 & 4.643 & 3.783 & 4.580 \\
\hline & & 3 & 35.870 & 19.907 & 20.530 & 32.713 & 6.258 & 3.787 & 6.177 \\
\hline & \multirow{3}{*}{0.05} & 1 & 39.399 & 9.437 & 23.876 & 27.912 & 11.389 & 10.052 & 11.031 \\
\hline & & 2 & 40.132 & 23.845 & 28.840 & 28.854 & 11.440 & 10.494 & 11.411 \\
\hline & & 3 & 44.907 & 25.160 & 34.898 & 41.508 & 15.517 & 10.653 & 12.468 \\
\hline & \multirow{3}{*}{0.01} & 1 & 117.50 & 35.342 & 61.962 & 42.255 & 39.025 & 38.643 & 38.729 \\
\hline & & 2 & 122.52 & 59.276 & 74.310 & 79.353 & 61.277 & 56.844 & 58.321 \\
\hline & & 3 & 130.65 & 65.141 & 91.389 & 92.038 & 70.915 & 66.853 & 67.384 \\
\hline
\end{tabular}

boundary conditions on the vibration characteristics of shell structures may be very different. For example, for the FG shallow shell with the boundary constraints of $\mathrm{CE}^{2} \mathrm{CE}^{2}$, SCSC, and $\mathrm{E}^{1} \mathrm{E}^{1} \mathrm{E}^{1} \mathrm{E}^{1}$, the first-order frequency decreases with the increase of $p$. In particular, the frequency decreases very quickly, when $p$ is between 0.1 and 100 . However, for the four kinds of shallow shells with varying boundary constraints of $E^{2} E^{2} E^{2} E^{2}, E^{3} E^{3} E^{3} E^{3}$, and $\mathrm{SE}^{3} \mathrm{SE}^{3}$, the frequency increases when $p$ increases.
The effects of material parameters $a, b$, and $c$ on the vibration characteristics of the $\mathrm{Al} / \mathrm{Al}_{2} \mathrm{O}_{3}$ shallow shells with $\mathrm{E}^{3} \mathrm{E}^{3} \mathrm{E}^{3} \mathrm{E}^{3}$ are discussed. Figure 4 shows the frequency parameters $\Omega$ of the shallow shells with the varying gradient power-law exponent parameters $p$ and four types of material gradient parameters. Four kinds of gradient parameters types are Type 1: $a=1, b=c=0$; Type 2: $a=1, b=0.5, c=2$; Type 3: $a=0, b=-0.5, c=2$; and Type 4: $a=1, b=1, c=4$. From Figure 4, it can be found that the material gradient 


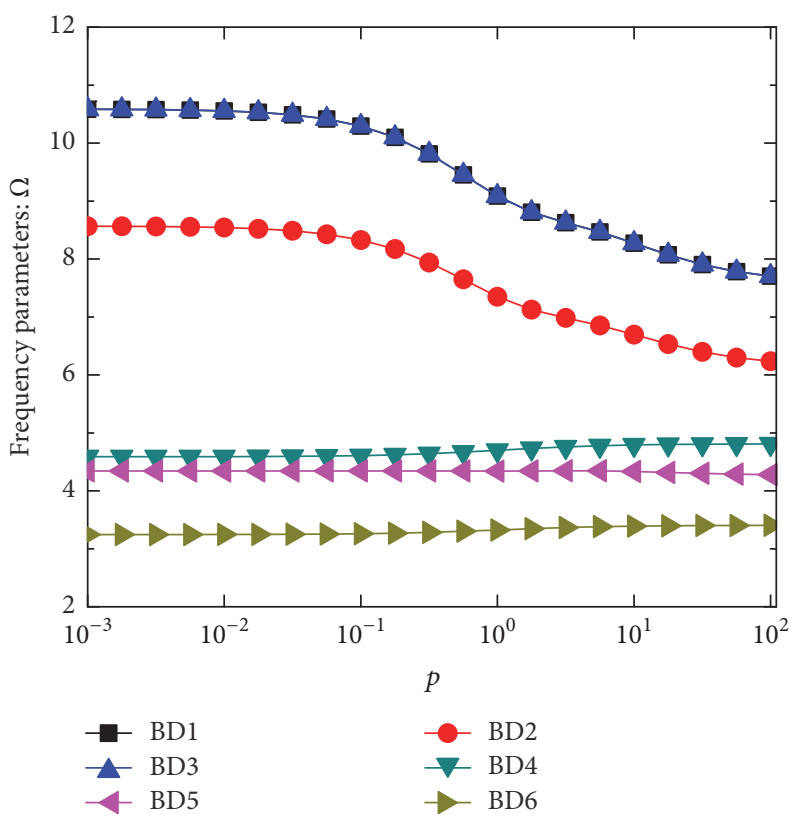

(a) Plate

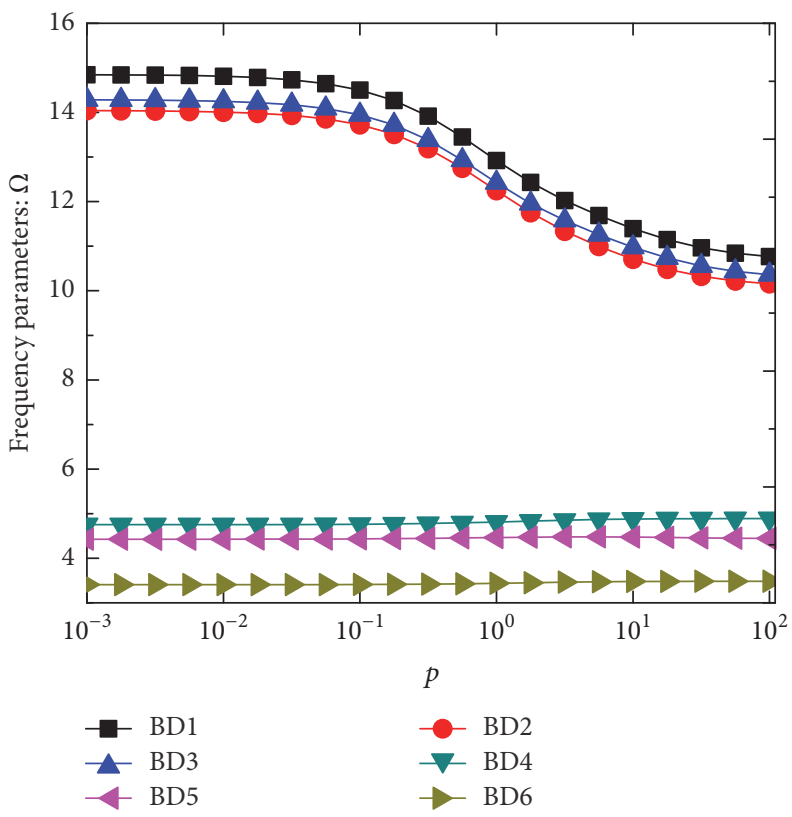

(c) Spherical shell

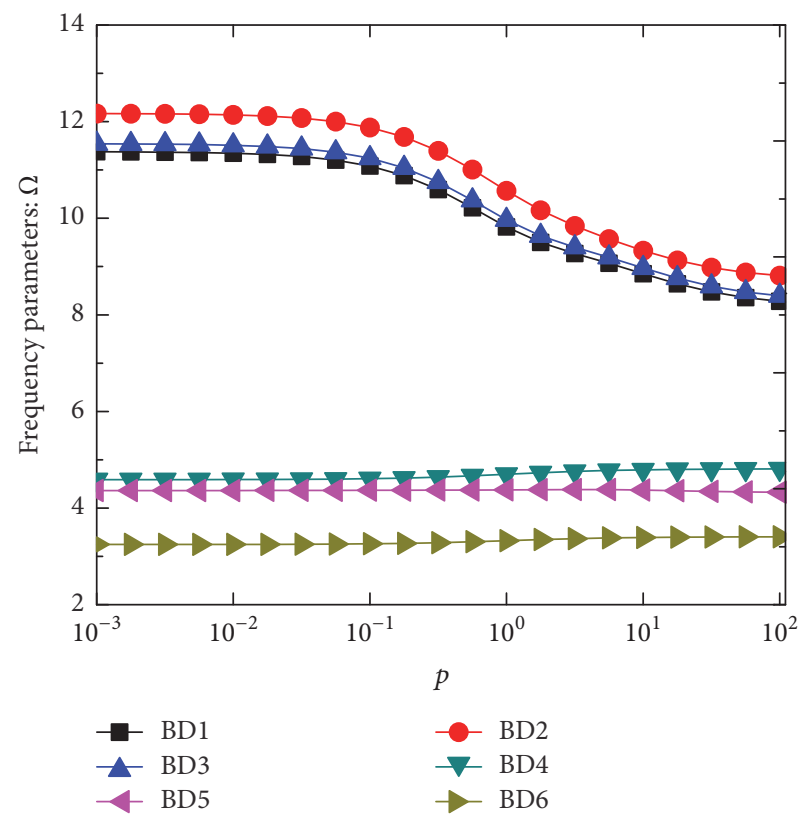

(b) Cylindrical shell

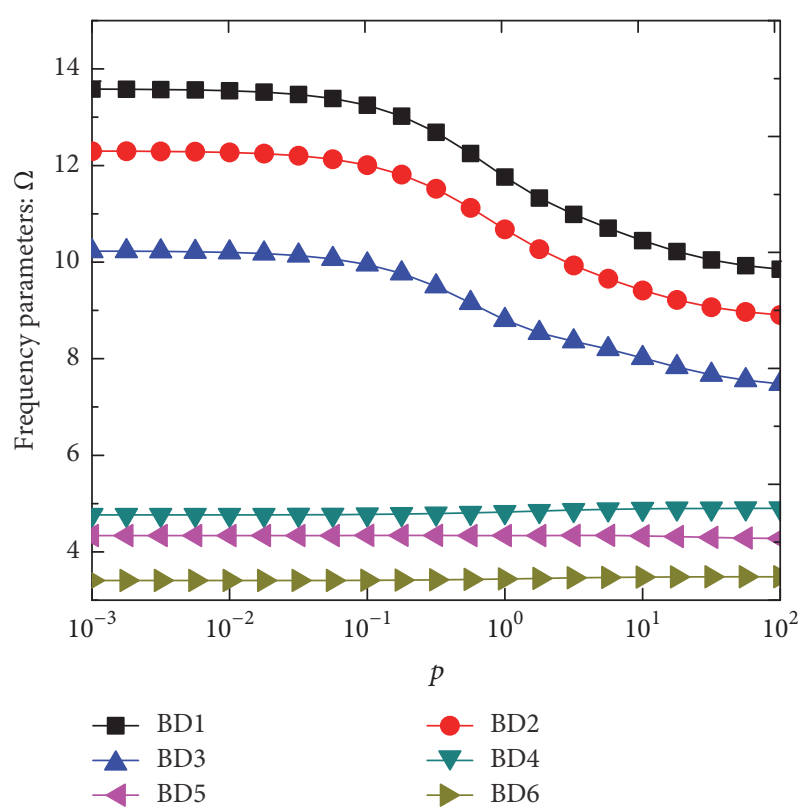

(d) Hyperbolic paraboloidal shell

FIgURE 3: Variations of the first frequency parameters $\Omega$ of the $\mathrm{Al} / \mathrm{Al}_{2} \mathrm{O}_{3}$ shallow shells with different boundary constraints: $\mathrm{BD1}$ : $\mathrm{CE}^{2} \mathrm{CE}^{2}$; BD2: SCSC; BD3: $E^{1} E^{1} E^{1} E^{1}$; BD4: $E^{2} E^{2} E^{2} E^{2}$; $B D 5: E^{3} E^{3} E^{3} E^{3}$; BD6: $\mathrm{SE}^{3} \mathrm{SE}^{3}$.

parameters have great effect on the vibration characteristics of the FG shallow shells. The changes of frequencies for the shallow shells with Type 1, Type 2, and Type 3 are the same, with the frequency increasing quickly when $p$ increases from zero to 5 and then decreasing with $p$ continuing to increase. But the frequency of the shallow shells with Type 4 is quite different with them. Especially when $p$ increases to 5, the frequency increases and then decreases slowly. Therefore, it is very important to study the vibration characteristics of FG shells with the varying material gradient parameters. This is because the change of material gradient parameters will completely change the mechanical properties of FG structure in the thickness direction. It is the reason why FGM has more advantages than traditional materials.

According to the above results, the $3 \mathrm{D}$ view model shapes of the $\mathrm{Al} / \mathrm{ZrO}_{2}$ shallow shells with CCCC boundary constraints and volume distribution functions $\operatorname{FGM}_{\mathrm{I}(i=1 / b=0 / c / p=1)}$ are given in Figure 5 . The geometric parameters of the plate, 

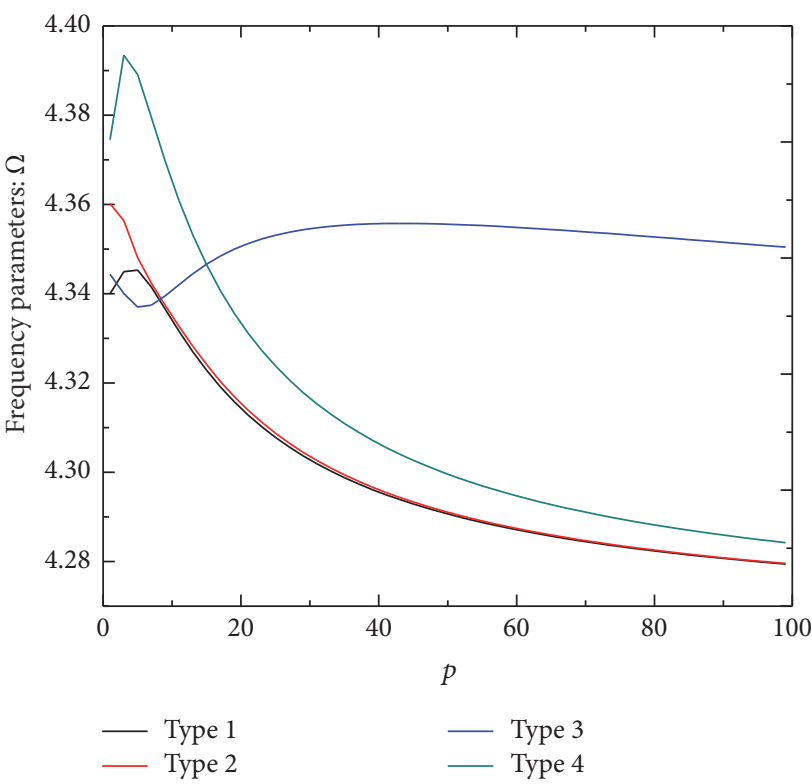

(a) Plate
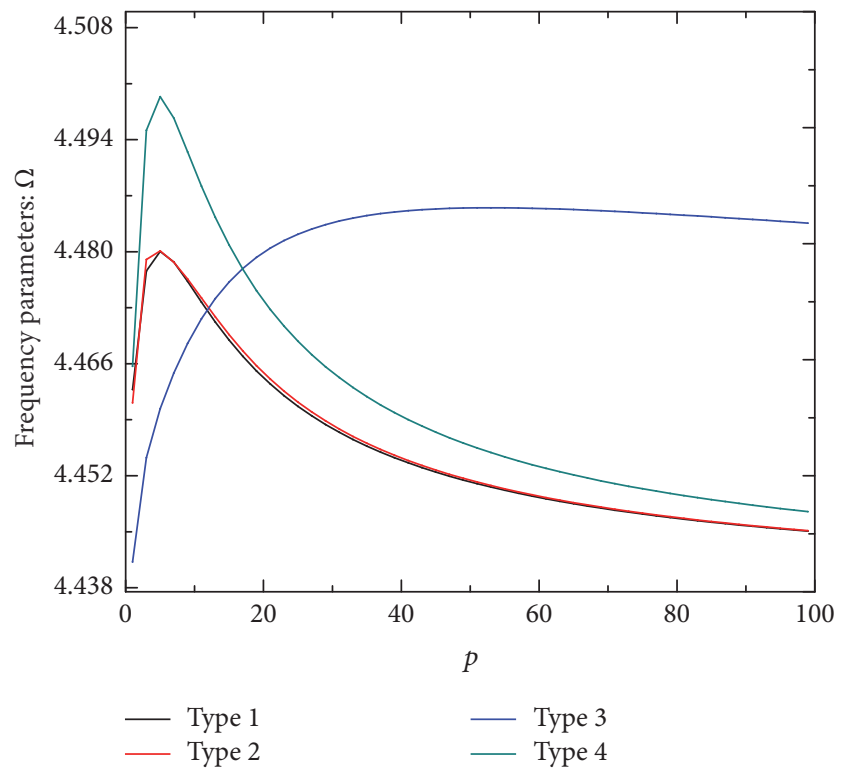

(c) Spherical shell

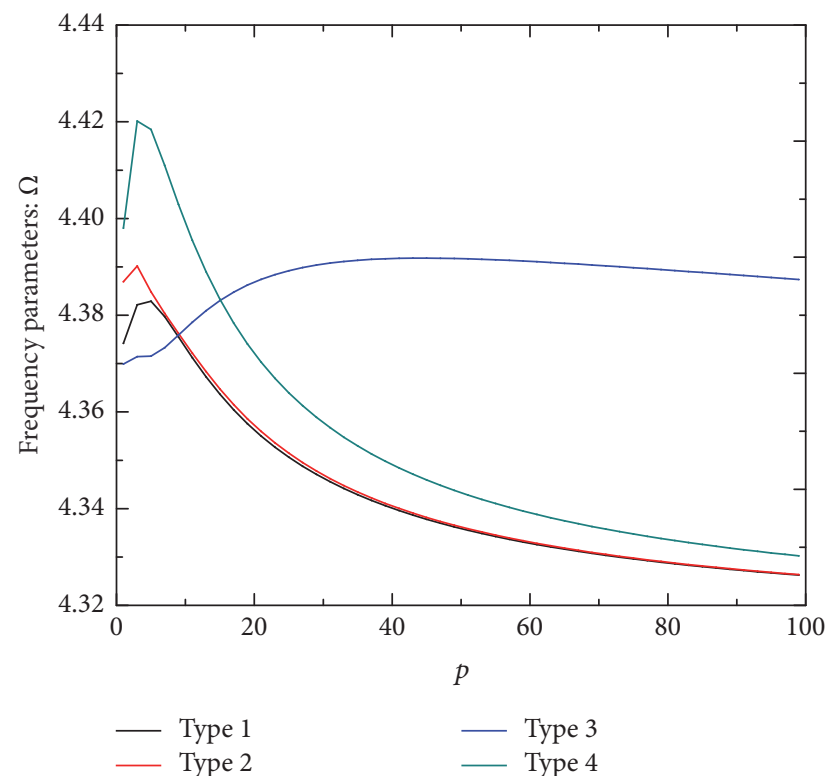

(b) Cylindrical shell

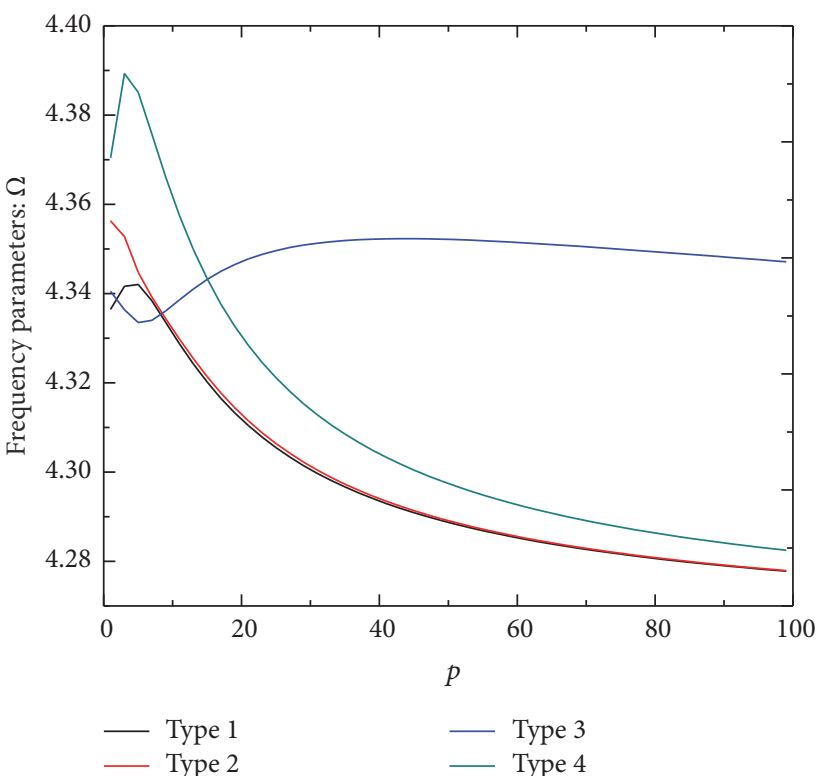

(d) Hyperbolic paraboloidal shell

Figure 4: Variations of the first frequency parameters $\Omega$ of the $\mathrm{Al} / \mathrm{Al}_{2} \mathrm{O}_{3}$ shallow shells with $\mathrm{E}^{3} \mathrm{E}^{3} \mathrm{E}^{3} \mathrm{E}^{3}$ and different material types: Type 1: $a=1, b=c=0$; Type 2: $a=1, b=0.5, c=2$; Type 3: $a=0, b=-0.5, c=2$; Type $4: a=1, b=1, c=4$.

cylindrical shell, and spherical shell in these figures are all $h=0.05 \mathrm{~m}, R=1 \mathrm{~m}$, but the length-width ratio $a / b$ is varied which has been given in Figure 5. These 3D view models are adopted to understand the free vibration characteristics of FG shallow shells.

\section{Conclusions}

In this paper, an improved Fourier series solution is proposed to solve the free vibration analysis of the unified FG double curvature shallow shells with general boundary constraints. The theoretical analysis is based on the FSDT and the Rayleigh-Ritz technique. The energy equation is solved by five displacement functions which are expressed as a series of $2 \mathrm{D}$ Fourier series. By introducing the product form of sine and cosine function, we can effectively eliminate the discontinuous or jumping phenomenon of the displacement function on the boundaries. Artificial virtual spring technique is used to simulate the boundary conditions; that is, five groups of springs are arranged on the four edges. They are linear springs $\left(k_{u}, k_{v}, k_{w}\right)$ and rotational springs $\left(K_{x}, K_{y}\right)$, respectively. Different boundary conditions 
Plate: $a / b=1$

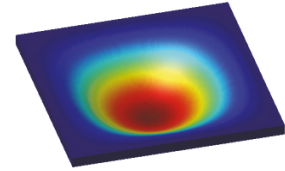

1st mode

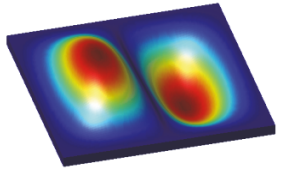

2nd mode

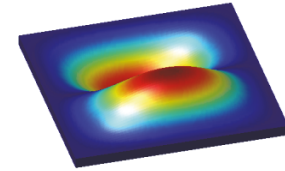

3rd mode

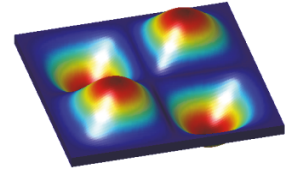

4th mode

Plate: $a / b=2$

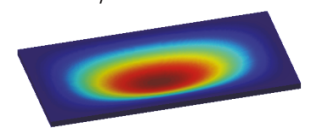

1st mode

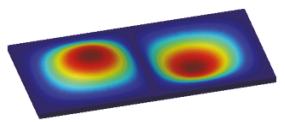

2nd mode

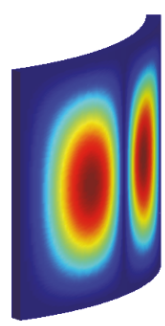

2nd mode

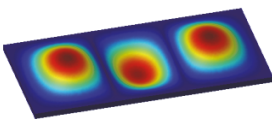

3rd mode

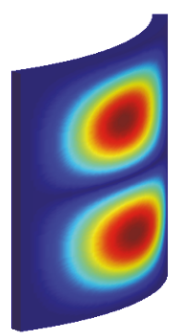

3rd mode

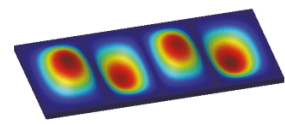

4th mode

Cylindrical shell: $a / b=1, R=1$

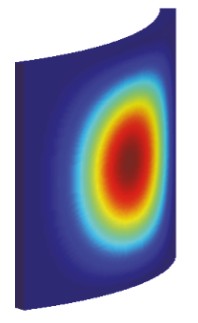

1st mode

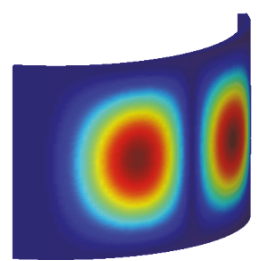

2nd mode

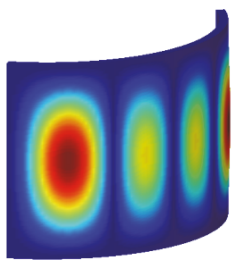

3rd mode

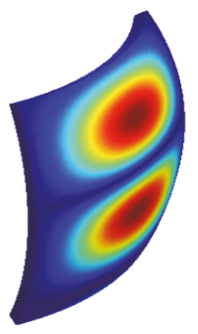

3rd mode

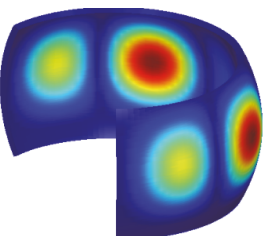

3rd mode

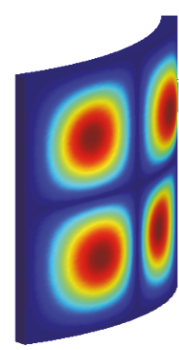

4th mode

Spherical shell: $a / b=1, R=1$

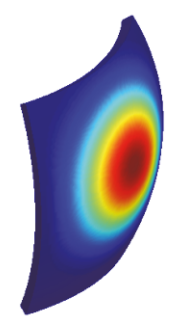

1st mode

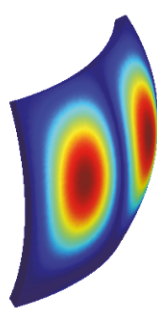

2nd mode

Spherical shell: $a / b=0.25, R=1$

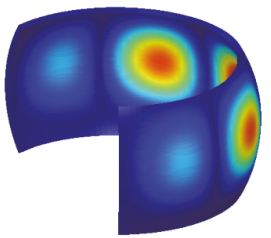

1st mode

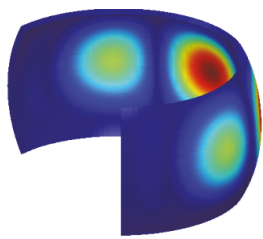

2nd mode

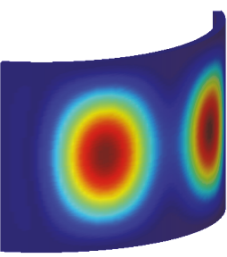

4th mode

FIGURE 5: Mode shapes of the $\mathrm{Al} / \mathrm{ZrO}_{2}$ shallow shells with CCCC boundary condition. 
can be realized by setting different stiffness values of the springs.

Through the analysis and discussion of the results, we can draw the following conclusions:

(1) The proposed method shows good convergence and the accuracy is verified by being compared with the existing literatures.

(2) The frequencies of the FG shall shells are changed a lot when the boundary conditions change. The results show that the spring stiffness is directly proportional to the frequency of the shallow shells.

(3) The geometric parameters also have a great influence on the free vibration of the FGM shallow shells. The frequency parameter of the square plate decreases gradually with the increase of length-thickness ratio $a / h$ while the frequency of the cylindrical shell reduces gradually when the radius $R$ and the thickness $h$ increase.

(4) The frequencies of the shallow shells are inversely proportional to the gradient index. The volume distribution functions only affect the cylindrical shells and spherical shells and have no effect on plates and hyperbolic paraboloidal shells.

It is of great value to study the free vibration characteristics for practical engineering applications. For example, the parametric studies of this paper provide the technical support and theoretical basis for the vibration reduction, noise reduction, and so on. In the following research, we aim to study the forced vibration analysis of the unified functionally graded shallow shell with general boundary conditions. And the work finished in this paper has laid a foundation for further study.

\section{Conflicts of Interest}

The authors declare that they have no conflicts of interest.

\section{Acknowledgments}

The authors gratefully acknowledge the financial support from the National Natural Science Foundation of China (Grant nos. 51679056 and 51705537) and Natural Science Foundation of Heilongjiang Province of China (E2016024).

\section{References}

[1] H. Matsunaga, "Free vibration and stability of functionally graded plates according to a 2-D higher-order deformation theory," Composite Structures, vol. 82, no. 4, pp. 499-512, 2008.

[2] T.-K. Nguyen, K. Sab, and G. Bonnet, "First-order shear deformation plate models for functionally graded materials," Composite Structures, vol. 83, no. 1, pp. 25-36, 2008.

[3] X. Zhao, Y. Y. Lee, and K. M. Liew, "Free vibration analysis of functionally graded plates using the element-free kp-Ritz method," Journal of Sound and Vibration, vol. 319, no. 3-5, pp. 918-939, 2009.

[4] X. Zhao, Y. Y. Lee, and K. M. Liew, "Mechanical and thermal buckling analysis of functionally graded plates," Composite Structures, vol. 90, no. 2, pp. 161-171, 2009.
[5] H.-S. Shen, "Nonlinear bending of functionally graded carbon nanotube-reinforced composite plates in thermal environments," Composite Structures, vol. 91, no. 1, pp. 9-19, 2009.

[6] H.-S. Shen and C.-L. Zhang, "Thermal buckling and postbuckling behavior of functionally graded carbon nanotube-reinforced composite plates," Materials and Design, vol. 31, no. 7, pp. 3403-3411, 2010.

[7] Z. Belabed, M. S. A. Houari, A. Tounsi, S. R. Mahmoud, and O. Anwar Bég, "An efficient and simple higher order shear and normal deformation theory for functionally graded material (FGM) plates," Composites Part B: Engineering, vol. 60, pp. 274283, 2014.

[8] A. M. A. Neves, A. J. M. Ferreira, E. Carrera et al., "Static, free vibration and buckling analysis of isotropic and sandwich functionally graded plates using a quasi-3D higher-order shear deformation theory and a meshless technique," Composites Part B: Engineering, vol. 44, no. 1, pp. 657-674, 2013.

[9] A. M. A. Neves, A. J. M. Ferreira, E. Carrera et al., "A quasi3D sinusoidal shear deformation theory for the static and free vibration analysis of functionally graded plates," Composites Part B: Engineering, vol. 43, no. 2, pp. 711-725, 2012.

[10] A. Tounsi, M. S. A. Houari, S. Benyoucef, and E. A. Adda Bedia, "A refined trigonometric shear deformation theory for thermoelastic bending of functionally graded sandwich plates," Aerospace Science and Technology, vol. 24, no. 1, pp. 209-220, 2013.

[11] A. Benachour, H. D. Tahar, H. A. Atmane, A. Tounsi, and M. S. Ahmed, "A four variable refined plate theory for free vibrations of functionally graded plates with arbitrary gradient," Composites Part B: Engineering, vol. 42, no. 6, pp. 1386-1394, 2011.

[12] H.-T. Thai and D.-H. Choi, "A simple first-order shear deformation theory for the bending and free vibration analysis of functionally graded plates," Composite Structures, vol. 101, pp. 332-340, 2013.

[13] H.-T. Thai and T. P. Vo, "A new sinusoidal shear deformation theory for bending, buckling, and vibration of functionally graded plates," Applied Mathematical Modelling. Simulation and Computation for Engineering and Environmental Systems, vol. 37, no. 5, pp. 3269-3281, 2013.

[14] G. G. Sheng and X. Wang, "Thermomechanical vibration analysis of a functionally graded shell with flowing fluid," European Journal of Mechanics-A/Solids, vol. 27, no. 6, pp. 1075-1087, 2008.

[15] G. G. Sheng and X. Wang, "Thermal vibration, buckling and dynamic stability of functionally graded cylindrical shells embedded in an elastic medium," Journal of Reinforced Plastics and Composites, vol. 27, no. 2, pp. 117-134, 2008.

[16] S. S. Vel, "Exact elasticity solution for the vibration of functionally graded anisotropic cylindrical shells," Composite Structures, vol. 92, no. 11, pp. 2712-2727, 2010.

[17] A. G. Shah, T. Mahmood, M. N. Naeem, Z. Iqbal, and S. H. Arshad, "Vibrations of functionally graded cylindrical shells based on elastic foundations," Acta Mechanica, vol. 211, no. 34, pp. 293-307, 2010.

[18] H. Matsunaga, "Free vibration and stability of functionally graded circular cylindrical shells according to a $2 \mathrm{D}$ higherorder deformation theory," Composite Structures, vol. 88, no. 4, pp. 519-531, 2009.

[19] P. Zahedinejad, P. Malekzadeh, M. Farid, and G. Karami, "A semi-analytical three-dimensional free vibration analysis of functionally graded curved panels," International Journal of Pressure Vessels and Piping, vol. 87, no. 8, pp. 470-480, 2010. 
[20] H. Santos, C. M. Mota Soares, C. A. Mota Soares, and J. N. Reddy, "A semi-analytical finite element model for the analysis of cylindrical shells made of functionally graded materials," Composite Structures, vol. 91, no. 4, pp. 427-432, 2009.

[21] H. A. Sepiani, A. Rastgoo, F. Ebrahimi, and A. Ghorbanpour Arani, "Vibration and buckling analysis of two-layered functionally graded cylindrical shell, considering the effects of transverse shear and rotary inertia," Materials and Design, vol. 31, no. 3, pp. 1063-1069, 2010.

[22] E. Bagherizadeh, Y. Kiani, and M. R. Eslami, "Mechanical buckling of functionally graded material cylindrical shells surrounded by Pasternak elastic foundation," Composite Structures, vol. 93, no. 11, pp. 3063-3071, 2011.

[23] Y. Tadi Beni, F. Mehralian, and H. Razavi, "Free vibration analysis of size-dependent shear deformable functionally graded cylindrical shell on the basis of modified couple stress theory," Composite Structures, vol. 120, pp. 65-78, 2015.

[24] F. Tornabene, "Free vibration analysis of functionally graded conical, cylindrical shell and annular plate structures with a four-parameter power-law distribution," Computer Methods in Applied Mechanics and Engineering, vol. 198, no. 37-40, pp. 29112935, 2009.

[25] F. Tornabene and E. Viola, "Free vibrations of four-parameter functionally graded parabolic panels and shells of revolution," European Journal of Mechanics, A/Solids, vol. 28, no. 5, pp. 9911013, 2009.

[26] F. Tornabene, E. Viola, and D. J. Inman, "2-D differential quadrature solution for vibration analysis of functionally graded conical, cylindrical shell and annular plate structures," Journal of Sound and Vibration, vol. 328, no. 3, pp. 259-290, 2009.

[27] F. Tornabene, N. Fantuzzi, and M. Bacciocchi, "Free vibrations of free-form doubly-curved shells made of functionally graded materials using higher-order equivalent single layer theories," Composites Part B: Engineering, vol. 67, pp. 490-509, 2014.

[28] A. M. Neves, A. J. Ferreira, E. Carrera et al., "Free vibration analysis of functionally graded shells by a higher-order shear deformation theory and radial basis functions collocation, accounting for through-the-thickness deformations," European Journal of Mechanics. A. Solids, vol. 37, pp. 24-34, 2013.

[29] S. Pradyumna and J. N. Bandyopadhyay, "Free vibration analysis of functionally graded curved panels using a higher-order finite element formulation," Journal of Sound and Vibration, vol. 318, no. 1-2, pp. 176-192, 2008.

[30] H. Matsunaga, "Free vibration and stability of functionally graded shallow shells according to a 2D higher-order deformation theory," Composite Structures, vol. 84, no. 2, pp. 132-146, 2008.

[31] F. Alijani, M. Amabili, K. Karagiozis, and F. Bakhtiari-Nejad, "Nonlinear vibrations of functionally graded doubly curved shallow shells," Journal of Sound and Vibration, vol. 330, no. 7, pp. 1432-1454, 2011.

[32] Z. Su, G. Jin, S. Shi, T. Ye, and X. Jia, "A unified solution for vibration analysis of functionally graded cylindrical, conical shells and annular plates with general boundary conditions," International Journal of Mechanical Sciences, vol. 80, pp. 62-80, 2014.

[33] Y. Qu, X. Long, G. Yuan, and G. Meng, "A unified formulation for vibration analysis of functionally graded shells of revolution with arbitrary boundary conditions," Composites Part B: Engineering, vol. 50, pp. 381-402, 2013.

[34] F. Alijani, M. Amabili, and F. Bakhtiari-Nejad, "Thermal effects on nonlinear vibrations of functionally graded doubly curved shells using higher order shear deformation theory," Composite Structures, vol. 93, no. 10, pp. 2541-2553, 2011.
[35] W. L. Li, "Vibration analysis of rectangular plates with general elastic boundary supports," Journal of Sound and Vibration, vol. 273, no. 3, pp. 619-635, 2004.

[36] X. Zhang and W. L. Li, "Vibrations of rectangular plates with arbitrary non-uniform elastic edge restraints," Journal of Sound and Vibration, vol. 326, no. 1-2, pp. 221-234, 2009.

[37] D. Shao, F. Hu, Q. Wang, F. Pang, and S. Hu, “Transient response analysis of cross-ply composite laminated rectangular plates with general boundary restraints by the method of reverberation ray matrix," Composite Structures, vol. 152, pp. 168-182, 2016.

[38] D. Shao, S. Hu, Q. Wang, and F. Pang, "A unified analysis for the transient response of composite laminated curved beam with arbitrary lamination schemes and general boundary restraints," Composite Structures, vol. 154, pp. 507-526, 2016.

[39] Q. Wang, F. Pang, B. Qin, and Q. Liang, "A unified formulation for free vibration of functionally graded carbon nanotube reinforced composite spherical panels and shells of revolution with general elastic restraints by means of the Rayleigh-Ritz method," Polymer Composites, 2017.

[40] H. Zhang, D. Shi, and Q. Wang, "An improved Fourier series solution for free vibration analysis of the moderately thick laminated composite rectangular plate with non-uniform boundary conditions," International Journal of Mechanical Sciences, vol. 121, pp. 1-20, 2017.

[41] D. Shao, S. Hu, Q. Wang, and F. Pang, "Free vibration of refined higher-order shear deformation composite laminated beams with general boundary conditions," Composites Part B: Engineering, vol. 108, pp. 75-90, 2017.

[42] D. Shi, Q. Liang, Q. Wang, and X. Teng, "A unified solution for free vibration of orthotropic circular, annular and sector plates with general boundary conditions," Journal of Vibroengineering, vol. 18, no. 5, pp. 3138-3152, 2016.

[43] Q. Wang, D. Shi, and Q. Liang, "Free vibration analysis of axially loaded laminated composite beams with general boundary conditions by using a modified Fourier-Ritz approach," Journal of Composite Materials, vol. 50, no. 15, pp. 2111-2135, 2016.

[44] Q. Wang, D. Shi, Q. Liang, and F. e Ahad, "A unified solution for free in-plane vibration of orthotropic circular, annular and sector plates with general boundary conditions," Applied Mathematical Modelling. Simulation and Computation for Engineering and Environmental Systems, vol. 40, no. 21-22, pp. 9228-9253, 2016.

[45] Y. Zhou, Q. Wang, D. Shi, Q. Liang, and Z. Zhang, "Exact solutions for the free in-plane vibrations of rectangular plates with arbitrary boundary conditions," International Journal of Mechanical Sciences, vol. 130, pp. 1-10, 2017.

[46] L. Dozio and E. Carrera, "A variable kinematic Ritz formulation for vibration study of quadrilateral plates with arbitrary thickness," Journal of Sound and Vibration, vol. 330, no. 18-19, pp. 4611-4632, 2011.

[47] L. Dozio and E. Carrera, "Ritz analysis of vibrating rectangular and skew multilayered plates based on advanced variable-kinematic models," Composite Structures, vol. 94, no. 6, pp. 21182128, 2012.

[48] S. Valvano and E. Carrera, "Node-dependent kinematics for the analysis of composite and sandwich structures," Facta Universitatis, Series: Mechanical Engineering, vol. 15, no. 1, pp. 1-30, 2017.

[49] E. Zappino, G. Li, A. Pagani, and E. Carrera, "Global-local analysis of laminated plates by node-dependent kinematic finite elements with variable ESL/LW capabilities," Composite Structures, vol. 172, pp. 1-14, 2017. 
[50] E. Carrera, S. Brischetto, M. Cinefra, and M. Soave, "Effects of thickness stretching in functionally graded plates and shells," Composites Part B: Engineering, vol. 42, no. 2, pp. 123-133, 2011.

[51] E. Carrera, M. Cinefra, G. Li, and G. M. Kulikov, "MITC9 shell finite elements with miscellaneous through-the-thickness functions for the analysis of laminated structures," Composite Structures, vol. 154, pp. 360-373, 2016.

[52] E. Carrera, A. Pagani, and S. Valvano, "Shell elements with through-the-thickness variable kinematics for the analysis of laminated composite and sandwich structures," Composites Part B: Engineering, vol. 111, pp. 294-314, 2017.

[53] M. Cinefra and E. Carrera, "Shell finite elements with different through-the-thickness kinematics for the linear analysis of cylindrical multilayered structures," International Journal for Numerical Methods in Engineering, vol. 93, no. 2, pp. 160-182, 2013.

[54] M. Cinefra and E. Carrera, "Shell Finite Elements for the Analysis of Multifield Problems in Multilayered Composite Structures," Applied Mechanics and Materials, vol. 828, pp. 215-236, 2016.

[55] A. J. M. Ferreira, E. Carrera, M. Cinefra, and C. M. C. Roque, "Analysis of laminated doubly-curved shells by a layerwise theory and radial basis functions collocation, accounting for through-the-thickness deformations," Computational Mechanics, vol. 48, no. 1, pp. 13-25, 2011.

[56] G. Jin, Z. Su, S. Shi, T. Ye, and S. Gao, “Three-dimensional exact solution for the free vibration of arbitrarily thick functionally graded rectangular plates with general boundary conditions," Composite Structures, vol. 108, no. 1, pp. 565-577, 2014.

[57] Y. Kiani, M. Shakeri, and M. R. Eslami, "Thermoelastic free vibration and dynamic behaviour of an FGM doubly curved panel via the analytical hybrid Laplace-Fourier transformation," Acta Mechanica, vol. 223, no. 6, pp. 1199-1218, 2012.

[58] Z. Su, G. Jin, and T. Ye, "Free vibration analysis of moderately thick functionally graded open shells with general boundary conditions," Composite Structures, vol. 117, no. 1, pp. 169-186, 2014.

[59] D. Shi, X. Lv, Q. Wang, and Q. Liang, "A unified solution for free vibration of orthotropic annular sector thin plates with general boundary conditions, internal radial line and circumferential arc supports," Journal of Vibroengineering, vol. 18, no. 1, pp. 361$377,2016$.

[60] X. Shi, D. Shi, W. L. Li, and Q. Wang, "A unified method for free vibration analysis of circular, annular and sector plates with arbitrary boundary conditions," Journal of Vibration and Control, vol. 22, no. 2, pp. 442-456, 2016.

[61] Q. Wang, D. Shi, Q. Liang, and F. Pang, "A unified solution for vibration analysis of moderately thick, functionally graded rectangular plates with general boundary restraints and internal line supports," Mechanics of Advanced Materials and Structures, vol. 24, no. 11, pp. 961-973, 2017.

[62] M. S. Qatu, "Vibration of Laminated Shells and Plates," Vibration of Laminated Shells and Plates, pp. 1-409, 2004.

[63] J. N. Reddy, "Theory and analysis of laminated composite plates," Mechanics of Composite Materials and Structures, pp. 179, 1999.

[64] D. Shi, Q. Wang, X. Shi, and F. Pang, "A series solution for the in-plane vibration analysis of orthotropic rectangular plates with non-uniform elastic boundary constraints and internal line supports," Archive of Applied Mechanics, vol. 85, no. 1, pp. 51-73, 2015.
[65] D. Shi, Q. Wang, X. Shi, and F. Pang, "An accurate solution method for the vibration analysis of Timoshenko beams with general elastic supports," Proceedings of the Institution of Mechanical Engineers Part C: Journal of Mechanical Engineering Science, 2014.

[66] H. Zhang, D. Shi, Q. Wang, and B. Qin, "Free vibration of functionally graded parabolic and circular panels with general boundary conditions," Curved and Layered Structures, vol. 4, no. $1,2017$.

[67] K. Zhang, D. Shi, W. Wang, and Q. Wang, "Mechanical characterization of hybrid lattice-to-steel joint with pyramidal CFRP truss for marine application," Composite Structures, vol. 160, pp. 1198-1204, 2017.

[68] D. Shao, S. Hu, Q. Wang, and F. Pang, "An enhanced reverberation-ray matrix approach for transient response analysis of composite laminated shallow shells with general boundary conditions," Composite Structures, vol. 162, pp. 133-155, 2017.

[69] D. Shi, H. Zhang, Q. Wang, and S. Zha, "Free and Forced Vibration of the Moderately Thick Laminated Composite Rectangular Plate on Various Elastic Winkler and Pasternak Foundations," Shock and Vibration, vol. 2017, pp. 1-23, 2017.

[70] Q. Wang, B. Qin, D. Shi, and Q. Liang, "A semi-analytical method for vibration analysis of functionally graded carbon nanotube reinforced composite doubly-curved panels and shells of revolution," Composite Structures, vol. 174, pp. 87-109, 2017.

[71] Q. Wang, D. Shi, Q. Liang, and F. Pang, "Free vibrations of composite laminated doubly-curved shells and panels of revolution with general elastic restraints," Applied Mathematical Modelling, vol. 46, pp. 227-262, 2017.

[72] Q. Wang, D. Shi, F. Pang, and F. e Ahad, "Benchmark solution for free vibration of thick open cylindrical shells on Pasternak foundation with general boundary conditions," Meccanica. International Journal of Theoretical and Applied Mechanics, vol. 52, no. 1-2, pp. 457-482, 2017.

[73] Q. Wang, D. Shi, F. Pang, and Q. Liang, "Vibrations of composite laminated circular panels and shells of revolution with general elastic boundary conditions via Fourier-Ritz method," Curved and Layered Structures, vol. 3, no. 1, pp. 105-136, 2016.

[74] Q. Wang, D. Shi, and X. Shi, "A modified solution for the free vibration analysis of moderately thick orthotropic rectangular plates with general boundary conditions, internal line supports and resting on elastic foundation," Meccanica, vol. 51, no. 8, pp. 1985-2017, 2016.

[75] S. Chakraverty and L. Behera, "Free vibration of rectangular nanoplates using Rayleigh-Ritz method," Physica E: LowDimensional Systems and Nanostructures, vol. 56, pp. 357-363, 2014.

[76] S. Ilanko, L. Monterrubio, and Y. Mochida, The Rayleigh-Ritz Method for Structural Analysis, John Wiley \& Sons, Hoboken, NJ, USA, 2015.

[77] K.-K. Pradhan and S. Chakraverty, "Free vibration of Euler and Timoshenko functionally graded beams by Rayleigh-Ritz method," Composites Part B: Engineering, vol. 51, no. 4, pp. 175184, 2013.

[78] S. Sun, D. Cao, and Q. Han, "Vibration studies of rotating cylindrical shells with arbitrary edges using characteristic orthogonal polynomials in the Rayleigh-Ritz method," International Journal of Mechanical Sciences, vol. 68, pp. 180-189, 2013. 


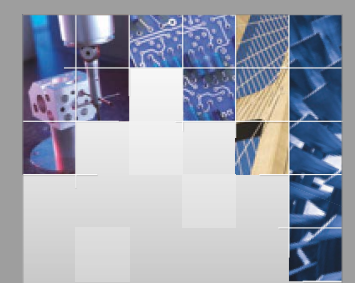

\section{Enfincering}
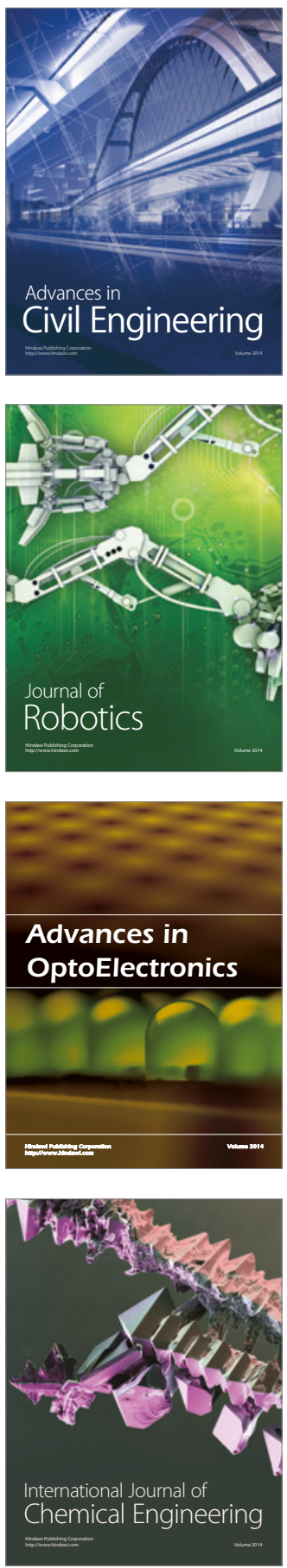

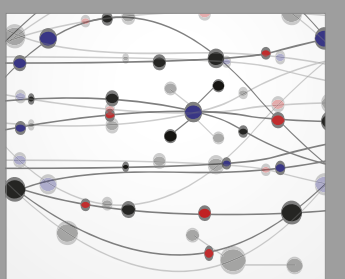

The Scientific World Journal

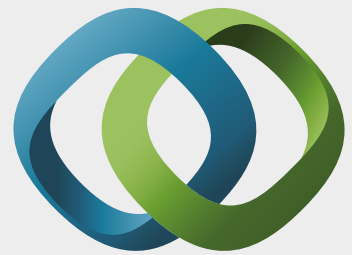

\section{Hindawi}

Submit your manuscripts at

https://www.hindawi.com
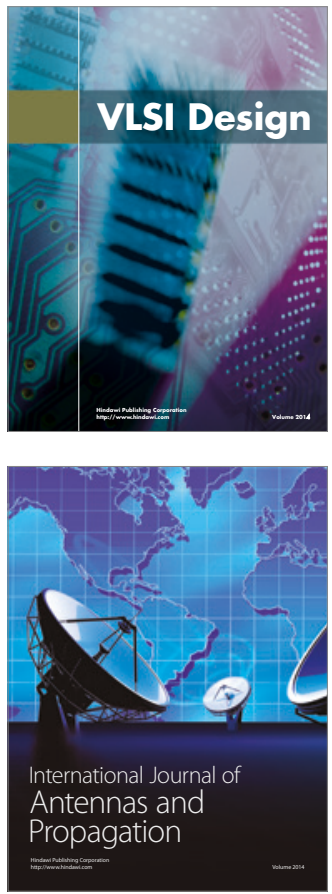

\section{Rotating}

Machinery
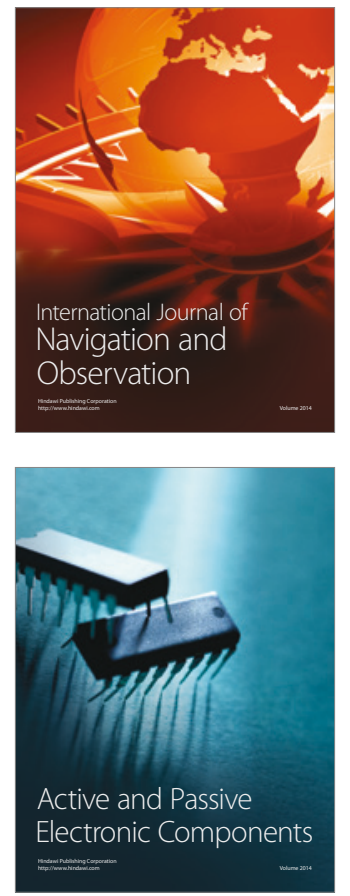
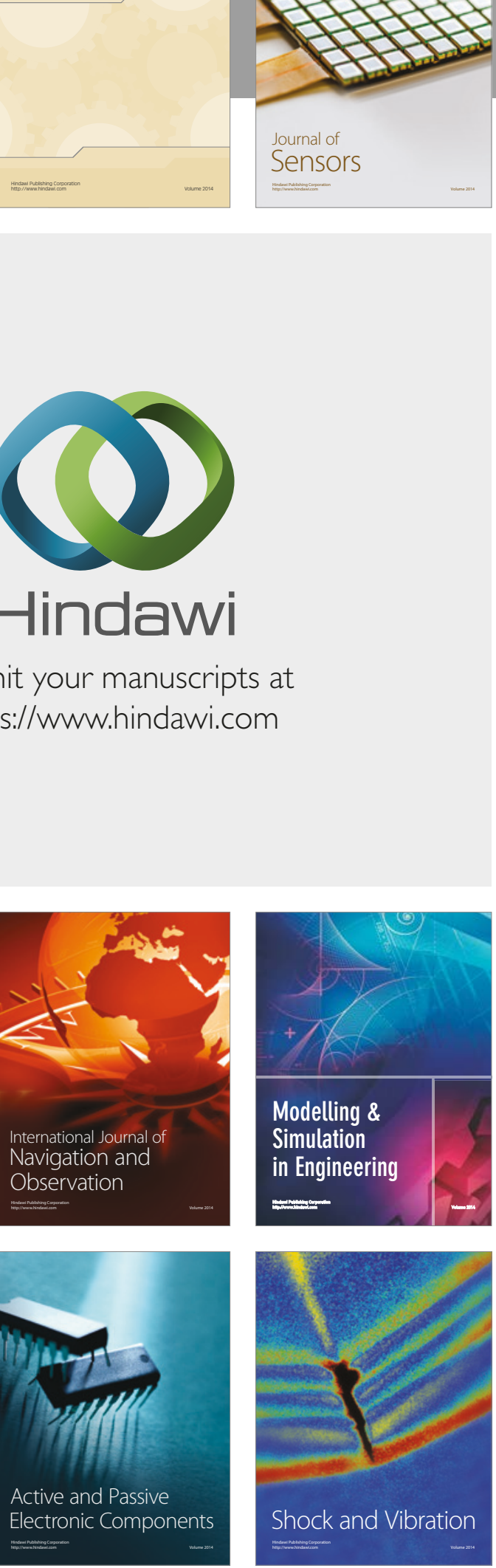
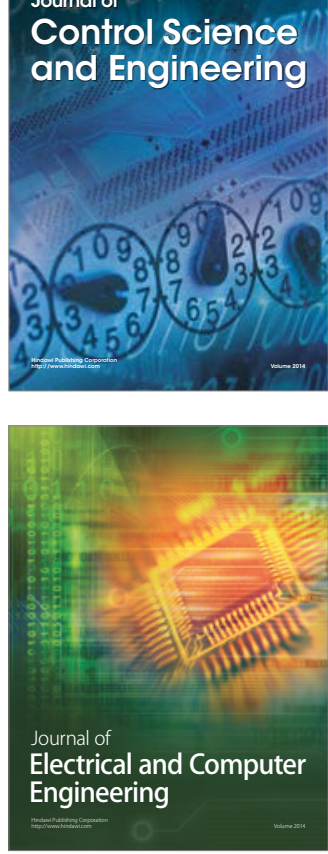

Distributed

Journal of

Control Science

and Engineering
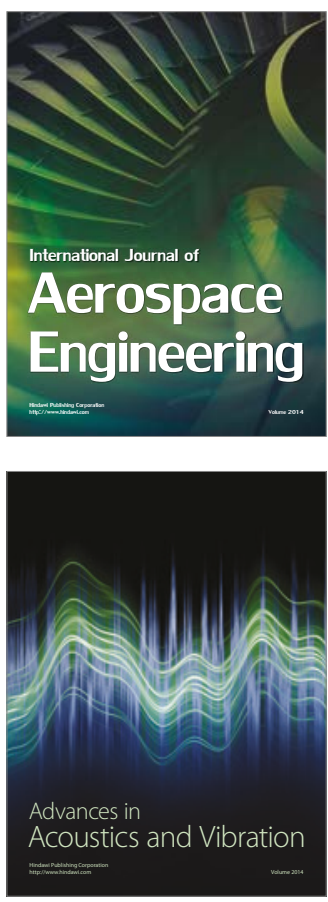

Sensor Networks 